



\section{Proficiency test for tropane alkaloids in food and feed matrices}

EURLPT-MP04 (2020)

D.P.K.H. Pereboom, W.C.M. de Nijs, P.P.J. Mulder 
D.P.K.H. Pereboom, W.C.M. de Nijs, P.P.J. Mulder, 2021. Proficiency test for tropane alkaloids in food and feed matrices; EURLPT-MPO4 (2020). Wageningen, Wageningen Food Safety Research, WFSR report 2021.005. 40 pp.; 7 fig.; 6 tab.; 12 ref.

Project number: WOT-1297362201-EURLMP

Project title: EURL mycotoxins \& plant toxins 2019/2020 (1.3.3 EURLPT04 TA)

Coordinator proficiency tests: D.P.K.H. Pereboom

Project leader: W.C.M. de Nijs

Scientist: P.P.J. Mulder

This report can be downloaded for free at https://doi.org/10.18174/544466 or at www.wur.eu/foodsafety-research (under WFSR publications).

(C) 2021 Wageningen Food Safety Research, institute within the legal entity Wageningen Research Foundation. Hereinafter referred to as WFSR.

The client is allowed to publish or distribute the full report to third parties. Without prior written permission from WFSR it is not allowed to:

a) publish parts of this report;

b) use this report or title of this report in conducting legal procedures, for advertising, acquisition or other commercial purposes;

c) use the name of WFSR other than as the author of this report.

P.O. Box 230, 6700 AE Wageningen, The Netherlands, T +31 (0)317 4802 56, E info.wfsr@wur.nl, www.wur.eu/food-safety-research. WFSR is part of Wageningen University \& Research.

This report from WFSR has been produced with the utmost care. However, WFSR does not accept liability for any claims based on the contents of this report.

WFSR report 2021.005

Distribution list:

- Participating laboratories

- Mr. F. Verstraete, European Commission, DG SANTE 


\section{Contents}

$\begin{array}{ll}\text { Summary } & 5\end{array}$

$\begin{array}{ll}\text { Introduction } & 7\end{array}$

2 PT Material

2.1 Scope of the PT

2.2 Material preparation

2.3 Sample identification $\quad 8$

2.4 Homogeneity study $\quad 9$

2.5 Stability of the materials $\quad 9$

$\begin{array}{ll}\text { Organisational details } & 10\end{array}$

$\begin{array}{lll}3.1 & \text { Participants } & 10\end{array}$

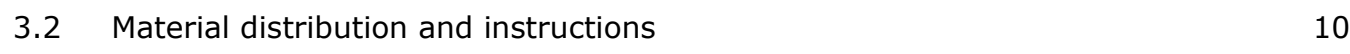

4.1 Calculation of the assigned value $\quad 11$

4.2 Standard deviation for proficiency assessment $\left(\sigma_{P}\right) \quad 11$

4.3 Quantitative performance (z-scores) 11

$\begin{array}{lll}4.4 & \text { Evaluation of non-quantified results } & 12\end{array}$

4.5 False positive and false negative results 12

$5 \quad$ Performance assessment $\quad 13$

5.1 Scope and LOQ 13

$\begin{array}{lll}5.2 & \text { Analytical methods } & 13\end{array}$

$\begin{array}{lll}5.3 & \text { Performance } & 15\end{array}$

$\begin{array}{lll}5.4 & \text { Robust relative standard deviation } & 16\end{array}$

$\begin{array}{ll}\text { References } & 18\end{array}$

$\begin{array}{lll}\text { Annex } 1 & \text { List of participants } & 19\end{array}$

$\begin{array}{lll}\text { Annex } 2 \text { Codification of the samples } & 20\end{array}$

$\begin{array}{lll}\text { Annex } 3 & \text { Statistical evaluation of the homogeneity data } & 21\end{array}$

$\begin{array}{lll}\text { Annex } 4 & \text { Statistical evaluation of the stability data } & 23\end{array}$

Annex 5 Invitation letter $\quad 25$

$\begin{array}{lll}\text { Annex } 6 & \text { Instruction letter } & 27\end{array}$

$\begin{array}{lll}\text { Annex } 7 & \text { Scope and LOQ } & 29\end{array}$

$\begin{array}{lll}\text { Annex } 8 & \text { Method details } & 30\end{array}$

Annex 9 Results: Material A (buckwheat flour) 34

Annex 10 Results: Material B (maize flour) 36

$\begin{array}{lll}\text { Annex } 11 & \text { Overview performance per participant } & 38\end{array}$ 



\section{Summary}

A proficiency test (PT) for the determination of the tropane alkaloids (TAs) atropine and scopolamine in buckwheat flour and maize flour was organised by the European Union Reference Laboratory for mycotoxins \& plant toxins (EURLMP) between August and October 2020. This PT was carried out by Wageningen Food Safety Research (WFSR) in accordance with ISO/IEC 17043 (R013). The measurand levels were targeted to provide insight on the measurement capabilities of the EU Member States' National Reference Laboratories (NRLs) at concentrations corresponding to the levels of TAs in processed cereal-based foods and baby foods for infants and young children, containing millet, sorghum, buckwheat or their derived products as regulated by Commission Regulation (EU) 2016/239. In addition to this food product, a maize sample containing a higher level of TAs was included in this PT since an amendment to the legislation is foreseen.

The participants were asked to quantify atropine and scopolamine in two materials and to report the compounds individually as well as the sum value. The participants performance was assessed as z-score in both materials for the individual TAs (maximum score 4 out of 4 ) and for the sum of the two TAs in one sample (maximum score 2 out of 2 ).

Thirty-eight participants, of which 29 NRLs for mycotoxins and/or plant toxins in food and feed (from 22 EU Member States plus Iceland and Norway) and 9 Official Laboratories (8 from 4 EU Member States and Switzerland) participated in the PT.

Two materials, buckwheat flour (material A) and maize flour (material B), were prepared containing atropine and scopolamine. Levels were artificially increased by spiking with atropine and scopolamine standard solutions. Both materials were sufficiently homogeneous and stable during the PT. Each participant received one test sample of each material.

For the identification and quantification of atropine and scopolamine 34 participants used liquid chromatography (LC) coupled with tandem mass spectrometry (MS/MS), one participant used LC single quadrupole MS, two participants used LC high resolution mass spectrometry (HRMS) and one participant provided no information.

In this PT the robust mean was used as consensus value. The consensus value based on the participants' results was used as the assigned value. The assigned values of atropine and scopolamine in material A were, respectively, 1.15 and $1.16 \mu \mathrm{g} / \mathrm{kg}$ and in material B, respectively, 15.3 and $52.7 \mu \mathrm{g} / \mathrm{kg}$. Obtained interlaboratory reproducibility $\left(\mathrm{RSD}_{\mathrm{R}}\right)$ ranged from $14 \%$ to $26 \%$. The $R \mathrm{RD}_{R} \mathrm{Were}$ for all TAs below the target standard deviation, except for scopolamine (26\%) in material A. For the sum of TAs (atropine and scopolamine) the $R_{S D_{R}}$ was $20 \%$ and $17 \%$ for material $A$ and $B$, respectively.

The proficiency of the participants was assessed through z-scores, calculated using the assigned values and a relative target standard deviation of $25 \%$. All participants submitted results for atropine and scopolamine. One participant analysed only material A. For both materials (A and B) $87 \%$ of the results for atropine and scopolamine were rated with satisfactory $z$-scores $(|z| \leq 2), 6 \%$ of the results fell into the questionable range with $2<|z|<3$ and $7 \%$ of the results fell into the unsatisfactory range with $|z| \geq 3$. Twenty-six participants achieved optimal performance for both materials by detecting both TAs with the correct quantification and the absence of false negative results. In this PT, two false negatives were reported.

Characteristics of the PT materials and the outcome of this PT are summarised in Table 1. 
Table 1 Summary of proficiency test materials parameters and participants' performance.

\begin{tabular}{|c|c|c|c|c|c|c|c|}
\hline \multirow[b]{2}{*}{ Tropane alkaloid } & \multirow[b]{2}{*}{ Matrix } & \multirow{2}{*}{$\begin{array}{l}\text { Assigned } \\
\text { value } \\
(\mu g / k g)\end{array}$} & \multirow{2}{*}{$\begin{array}{l}\text { Uncertainty } \\
\text { ( } \mu g / \mathrm{kg})\end{array}$} & \multirow{2}{*}{$\begin{array}{c}\text { Robust } \\
\text { RSDR }^{1)} \\
(\%)\end{array}$} & \multicolumn{3}{|c|}{ No of labs reporting } \\
\hline & & & & & Quant. value & $<$ LOQ & FN \\
\hline Atropine & $\mathrm{B}$ & 15.3 & 0.439 & 13.8 & 36 & 1 & 1 \\
\hline Scopolamine & A & 1.16 & 0.063 & 25.6 & 35 & 3 & \\
\hline \multirow[t]{2}{*}{ Sum } & A & 2.36 & 0.099 & 20.1 & 36 & 2 & \\
\hline & B & 68.4 & 2.35 & 16.7 & 37 & & \\
\hline
\end{tabular}

\begin{tabular}{|c|c|c|c|c|c|c|c|}
\hline \multirow[b]{3}{*}{ Tropane alkaloid } & \multirow[b]{3}{*}{ Matrix } & \multirow{3}{*}{$\begin{array}{l}\text { Assigned } \\
\text { value } \\
\text { ( } \mu g / k g)\end{array}$} & \multicolumn{3}{|c|}{ z-scores $\left.{ }^{2}\right)$} & \multirow{2}{*}{\multicolumn{2}{|c|}{$\begin{array}{l}\text { Labs out of } 38 \text { with } \\
\text { Acceptable z-score }\end{array}$}} \\
\hline & & & satisfactory & questionable & unsatisfactory & & \\
\hline & & & $\begin{array}{l}\text { (\% of z- } \\
\text { scores) }\end{array}$ & $\begin{array}{l}\text { ( } \% \text { of z- } \\
\text { scores) }\end{array}$ & $\begin{array}{l}\text { ( } \% \text { of } z- \\
\text { scores) }\end{array}$ & $\mathrm{No}^{3)}$ & $\%{ }^{3)}$ \\
\hline \multirow[t]{2}{*}{ Atropine } & A & 1.15 & 88 & 3 & 9 & 30 & 79 \\
\hline & B & 15.3 & 92 & 0 & 8 & 34 & 90 \\
\hline Scopolamine & B & 52.7 & 92 & 3 & 5 & 34 & 90 \\
\hline \multirow[t]{2}{*}{ Sum } & A & 2.36 & 83 & 6 & 11 & 30 & 79 \\
\hline & $\mathrm{B}$ & 68.4 & 92 & 3 & 5 & 34 & 90 \\
\hline
\end{tabular}

Matrix: $A=$ Buckwheat flour, $B=$ Maize flour

1) robust relative standard deviation (interlaboratory RSD based on participants' results).

2) calculated using a fit-for-purpose target RSD for proficiency of $25 \%$. False negatives were counted here as unsatisfactory $z$-score.

3) the number and percentage here means: analyte determined, method with a sufficiently low LOQ to allow quantification, and obtaining a satisfactory z-score. 


\section{Introduction}

Tropane alkaloids (TAs) are secondary metabolites produced by a wide variety of plants from the families of Brassicaceae, Convolvulaceae, Moraceae and Solanaceae. Most important weed species in this respect are Datura stramonium (thorn apple) and Atropa belladonna (deadly nightshade). TAs are regarded as undesirable substances in food and feed and for that reason have been the subject of an EFSA opinion, published in 2013, in which an acute reference dose of $0.016 \mu \mathrm{g} / \mathrm{kg}$ body weight was derived [1]. More than 200 different TA have been identified in the various plant species. However, sufficient data on toxicity and occurrence in food are available only for the TAs atropine and scopolamine (Figure 1), which are regarded the most important representatives of this class of metabolites. Atropine is the racemic mixture of $(-)$-hyoscyamine and $(+$ )-hyoscyamine (synonyms Dand L- hyoscyamine) [1]. Atropine and scopolamine are strong antimuscarinic agents.<smiles>CN1[C@H]2CC[C@@H]1C[C@@H](OC(=O)C(CO)c1ccccc1)C2</smiles>

(a)<smiles>CN1[C@@H]2CO[C@@H]1C[C@@H](OC(=O)[C@H](CO)c1ccccc1)C2</smiles>

(b)

Figure 1 Chemical structures of atropine (a) and scopolamine (b).

Food crops, such as cereals, can be contaminated when TA containing weeds are co-harvested. Common practices for cleaning cereals are not always sufficient to remove the weed plant parts and seeds. Legal limits for TAs in foods were issued in 2016 with Regulation (EU) 2016/239 on maximum levels of TAs in certain cereal-based foods for infants and young children, amending Regulation (EC) No 1881/2006 [2,3]. The maximum limit for these products at the time of the PT was $1 \mu \mathrm{g} / \mathrm{kg}$ for atropine and $1 \mu \mathrm{g} / \mathrm{kg}$ for scopolamine. An amendment to the legislation is foreseen and therefore, a maize sample containing a higher level of TAs was included in this PT.

Proficiency testing is conducted to provide participants with a powerful tool to evaluate and demonstrate the reliability of the data that are produced by the laboratory. Proficiency testing is an important requirement and is demanded by the ISO/IEC 17025:2017 [6]. Organisation of proficiency tests (PT) is one of the tasks of the European Union Reference Laboratories (EURLs) [7]. Here the primary goal is to assess the proficiency of the National Reference Laboratories (NRLs). To facilitate NRLs in their task, official laboratories (OLs) can also participate, in consultation with their NRL. 


\section{PT Material}

\subsection{Scope of the PT}

This proficiency test focused on the TAs atropine and scopolamine in food and feed, using buckwheat flour and maize flour as representative matrices. The target concentrations aimed for (see Table 2) took the regulatory limits and commonly found concentrations into account.

Table 2 Target concentrations $\mu \mathrm{g} / \mathrm{kg}$ of atropine and scopolamine in the PT materials.

\begin{tabular}{|c|c|c|}
\hline \multirow[b]{2}{*}{ Tropane alkaloid } & \multicolumn{2}{|c|}{ Target concentrations $(\mu \mathrm{g} / \mathrm{kg})$} \\
\hline & Material A & Material B \\
\hline Atropine & 1 & 15 \\
\hline Scopolamine & 1 & 50 \\
\hline
\end{tabular}

\subsection{Material preparation}

For preparation of the two PT materials A and B, respectively, buckwheat flour and maize flour were used. The materials were milled using a centrifugal mill (ZM 200, Retsch, Haan) to obtain a particle size of $500 \mu \mathrm{m}$. Contamination levels were artificially increased by spiking with atropine and scopolamine standard solutions.

To prepare the materials, a premix was prepared by spiking the blank material which was mixed with blank material. For each premix, $2000 \mathrm{~g}$ of blank material was fortified by adding a solution of atropine and scopolamine standards prepared in acetone, aiming at the levels as presented in Table 2. After 30 min the premix A was mixed with $1500 \mathrm{ml}$ acetone to prepare a slurry and premix B was mixed with $1200 \mathrm{ml}$ acetone. The slurries were homogenised using an industrial mixer (brand Topcraft) according to an in-house standard operating procedure [9]. The fortified slurry was air dried overnight in a fume hood and homogenised in a Stephan cutter UMC 5.

For the final materials, $4000 \mathrm{~g}$ blank material was mixed with $2000 \mathrm{~g}$ of the spiked premix. Materials $\mathrm{A}$ and $B$ were homogenised by mixing in a rotating drum and were stored at $<-18^{\circ} \mathrm{C}$ until use. The homogenisation of the materials was carried out at Wageningen Evaluating Programs for Analytical Laboratories (WEPAL). WEPAL is accredited to ISO/IEC 17043 for the preparation of PT materials by the Dutch Accreditation Council (RvA, R002).

\subsection{Sample identification}

After homogenisation, materials $\mathrm{A}$ and $\mathrm{B}$ were divided into sub-portions of approximately 50 grams and stored in polypropylene, airtight closed containers at $<-18^{\circ} \mathrm{C}$ until use.

The samples for the participants were randomly selected and coded using a web application designed for proficiency tests. The code used was "2020/EURLPT MP/TAs/xxx", in which the three-digit number of the code was automatically generated by the WFSR Laboratory Quality Services web application. One sample set was prepared for each participant. Each sample set consisted of one randomly selected sample of material A and one of material B. The codes of the samples for each sample set are shown in Annex 2. The samples for homogeneity and stability testing were also randomly selected out of materials $A$ and $B$. 


\subsection{Homogeneity study}

To verify the homogeneity of the PT materials, ten containers of materials A and B were analysed in duplicate for atropine and scopolamine.

Method in brief, atropine and scopolamine were extracted from the homogenised sample by addition of methanol/water $(60 / 40, \mathrm{v} / \mathrm{v})$ containing $0.4 \%$ of formic acid and agitation in an overhead shaker. After centrifugation of the sample extract, a portion of the supernatant was purified by passing it through a $30 \mathrm{kDa}$ ultrafilter. Analysis was performed by liquid chromatography (LC) coupled with tandem mass spectrometry (MS/MS) using reversed phase chromatography with alkaline conditions.

The homogeneity of both materials was evaluated according to the International Harmonized Protocol for Proficiency Testing of Analytical Laboratories [11] and ISO 13528:2015 [12]. Both materials proved to be sufficiently homogeneous for this PT. The results of the homogeneity study, grand means with the corresponding $\mathrm{RSD}_{\mathrm{r}}$, are presented in Table 3. The statistical evaluation of materials $\mathrm{A}$ and $\mathrm{B}$ is presented in Annex 3.

Table 3 Concentrations of atropine and scopolamine in material A and B obtained during the homogeneity testing.

\begin{tabular}{lcccc} 
& \multicolumn{3}{c}{ Material A } & \multicolumn{2}{c}{ Material B } \\
\cline { 2 - 5 } Compound & Conc. $(\mu \mathrm{g} / \mathrm{kg})$ & RSDr $(\%)$ & Conc. $(\mu \mathrm{g} / \mathrm{kg})$ & RSDr $(\%)$ \\
Atropine & 0.882 & 4.06 & 13.7 & 1.70 \\
\hline Scopolamine & 0.928 & 5.58 & 45.5 & 1.30 \\
\hline
\end{tabular}

\subsection{Stability of the materials}

The stability of atropine and scopolamine in the PT materials was assessed according to [11,12]. On August $31^{\text {st }}, 2020$, the day of distribution of the PT samples, six randomly selected containers of material $A$ and $B$ were stored at $<-20^{\circ} \mathrm{C}$. Under these conditions it is assumed that atropine and scopolamine are stable in the materials. In addition, six samples of each material were stored at $<4^{\circ} \mathrm{C}$.

On November $9^{\text {th }}, 2020,70$ days after distribution of the samples, six samples of materials $A$ and $B$, stored at $<-20^{\circ} \mathrm{C}$ and $<4^{\circ} \mathrm{C}$, were analysed in one batch. For each set of test samples, the average of the results and the standard deviation were calculated.

It was determined whether a consequential instability of the analytes had occurred $[11,12]$ in the materials stored at $<4^{\circ} \mathrm{C}$. A consequential instability is observed when the average value of an analyte in the samples stored at $\angle 4{ }^{\circ} \mathrm{C}$ is more than $0.3 \sigma_{\mathrm{p}}$ below the average value of the analyte in the samples stored at $<-20^{\circ} \mathrm{C}$. If so, the instability has a significant influence on the calculated z-scores.

The results of the stability of materials A and B are presented in Annex 4. None of the tested storage conditions caused a consequential difference for the analytes in both materials. Atropine and scopolamine in the materials were, therefore, considered stable for the duration of the PT. 


\section{Organisational details}

\subsection{Participants}

This proficiency test focused on the TAs atropine and scopolamine in food and feed, using buckwheat flour and maize flour. Invitations to the NRL network were sent out on June $30^{\text {th }}, 2020$ (Annex 5). Thirty-eight participants registered for the PT (Annex 1) and reported their results. Out of 38 participating laboratories, 29 were NRLs from 22 EU Member States plus Iceland and Norway and 9 were OLs ( 9 from 4 EU Member states and Switzerland). Each participant was free to use their method of choice reflecting their routine procedures. The participants were asked to report results through an web application designed for proficiency tests as well as to fill in a questionnaire, where it was asked to provide detailed information on the analytical method used for detection and quantification of atropine and scopolamine (extraction solvent/procedure clean-up, detection technique, limit of detection, limit of quantification).

\subsection{Material distribution and instructions}

Each participant received a randomly assigned laboratory code, generated by the web application. The sets of samples with the corresponding number, consisting of two coded samples (Annex 2) were sent to the PT participants on August $31^{\text {st }}, 2020$. The sets of samples were dispatched by courier to the participants in insulation boxes containing dry ice. The participants were asked to store the samples at $<4^{\circ} \mathrm{C}$ and to analyse the samples according to their routine practice. As reported by participants, most of the parcels (30) were received within 24 hours after dispatch. Eight participants received the parcel after 2 days. All samples were received in good order.

The samples were accompanied by a letter with instructions for the requested analysis (Annex 6) and an acknowledgement of receipt form. In addition, by e-mail, each participant received instructions on how to use the web application to report the results. The questionnaire was intended to gather additional information on limits of quantification (LOQs), method recovery estimates (\%) and other method-related aspects (e.g. extraction and clean-up, chromatographic and detection conditions, calibration strategy) to investigate individual and/or general patterns on the submitted results.

A single analysis result for the tropane alkaloids atropine and scopolamine in each sample was requested. The deadline for submitting the quantitative results was October $12^{\text {th }}, 2020$, allowing the participants six weeks for analysis of the test samples. All results, except one, were submitted within the deadline. Participant PT9159 was unable to report results in time due to COVID-19 issues. 


\section{$4 \quad$ Evaluation of results}

The statistical evaluation of the submitted results was carried out according to the International Harmonized Protocol for the Proficiency Testing of Analytical Laboratories [11], elaborated by ISO, IUPAC and AOAC, and ISO 13528:2015 [12] in combination with the insights published by the Analytical Methods Committee $[4,5]$ regarding robust statistics.

The evaluation of results was based on assigned values and the standard deviation for proficiency assessment $\left(\sigma_{P}\right)$. From this, z-scores were calculated to classify the participants' performance. Detailed information on the methods used for the statistical evaluation can be found in the background document 'EURL-MP-background doc_001 (v1) Performance assessment in proficiency tests organised by the EURL mycotoxins \& plant toxins in food and feed' available from the EURL mycotoxins \& plant toxins website ${ }^{1}$.

\subsection{Calculation of the assigned value}

The robust mean was used as consensus value in this PT. The consensus value based on the participants' results (all participants, both NRLs and OLs) was used as the assigned value. The values and their uncertainties are summarised in Table 1 in the Summary section. Assigned values were established for atropine, scopolamine and the sum of both TAs in both materials.

\subsection{Standard deviation for proficiency assessment $\left(\sigma_{P}\right)$}

A fixed relative target standard deviation for proficiency assessment $\left(\sigma_{P}\right)$ of $25 \%$ was used, irrespective the analyte, matrix or concentration. This generic fit-for-purpose value is considered to reflect current analytical capabilities and the best practises for mycotoxin and plant toxin determination in food and feed. The rationale behind this is provided in the before mentioned EURLMP-background doc_001.

\subsection{Quantitative performance (z-scores)}

For evaluation of numerical results submitted by each participant, z-scores were calculated based on the assigned value, its uncertainty, and the standard deviation for proficiency assessment $\left(\sigma_{p}\right)$. In cases when the uncertainty of the assigned value was negligible and no instability of the analytes in the PT material was observed, z-scores were calculated using the following equation:

$z=\frac{x-C}{\sigma_{p}}$ Equation 1

where:

$\mathrm{z}=\mathrm{z}$-score;

$\mathrm{x}=$ the result of the laboratory;

$\mathrm{C}=$ assigned value, here the consensus value;

$\sigma_{\mathrm{P}}=$ standard deviation for proficiency assessment.

The z-score compares the participants' deviation from the assigned value, taking the target standard deviation accepted for the proficiency test into account, and is interpreted as indicated in Table 4.

\footnotetext{
1 Website EURLMP
} 


\begin{tabular}{cc}
\hline$\left|z_{a}\right| \leq 2$ & Satisfactory \\
\hline $2<\left|z_{a}\right|<3$ & Questionable \\
\hline$z_{a} \mid \geq 3$ & Unsatisfactory \\
\hline
\end{tabular}

If the uncertainty of the assigned value and, if applicable, instability of the analyte in the PT material, is not negligible, then this is taken into account in the determination of the z-score. If applicable, this is indicated by assigning a $z^{\prime}-, z_{i}$-or $z_{i}^{\prime}$-score. For details see the background document 'EURL-MP PT performance assessment' on the EURL-MP website.

In this PT, for both materials, the uncertainty of the assigned value for atropine, scopolamine and the sum was negligible. No instability of the analytes in the PT materials was observed during the PT period.

\subsection{Evaluation of non-quantified results}

In cases, where participant(s) reported ' $<$ [value]' or 'not detected' (nd) (i.e. below their limit of quantification (LOQ)), 'proxy-z-scores' were calculated to assess possible false negatives and to benchmark the LOQ relative to the assigned value and the LOQ of the other participants.

A proxy-z-score was calculated by using equation IV and equation $V$ of the background document 'EURL-MP-background doc_001' (for details see the EURL-MP website), using the reported LOQ value as a result. Proxy-z-scores are for information only and indicated as a value between brackets.

Values $(z<-2)$ were considered as false negatives (see 4.5). Values $(z>2)$ indicate that the LOQ is high in relation to the assigned value and high in comparison to other participants.

Other types of reported results, e.g. 'detected' or 'not detected', without specification of LOQ, were excluded from the evaluation. In these cases, the participant was considered to have no quantitative method available for the applicable analyte/matrix.

\subsection{False positive and false negative results}

A false positive is a quantitative result reported by the participant while the analyte is not detected in the PT material by the organiser, and/or not detected by the majority of the other participants. A threshold is then applied, above which results are considered false positives, indicated as FP. False positives are to be interpreted as unsatisfactory performance.

When an analyte is present in the material, i.e. an assigned value has been established, and the participant reports the analyte as '<[value]', or 'not detected', an assessment is made to judge whether such results should be classified as a false negative. This is the case when the proxy-z-score (see 4.4) is <-2. False negatives are indicated as ' $F N$ '. False negatives are to be interpreted as unsatisfactory performance. 


\section{$5 \quad$ Performance assessment}

\subsection{Scope and LOQ}

This PT was dedicated to atropine and scopolamine in buckwheat flour and maize flour. Annex 7 summarises the quantitative scopes of each participant, with an indication of the LOQs for atropine and scopolamine. Five participants provided no details of their LOQs of the method used. The median LOQs for atropine and scopolamine were $0.5 \mu \mathrm{g} / \mathrm{kg}$.

All the participants determined and quantified atropine and scopolamine as was requested. One participant analysed only material $\mathrm{A}$.

Several results were reported as <LOQ or 'nd'. In case the participant had specified an LOQ (Annex 7), for these results proxy z-scores were calculated.

The LOQs provided by the participants ranged from 0.025 to $5 \mu \mathrm{g} / \mathrm{kg}$. The recommended LOQ for this proficiency test was $0.5 \mu \mathrm{g} / \mathrm{kg}$ or lower. Twenty-four participants reported an LOQ of $0.5 \mu \mathrm{g} / \mathrm{kg}$ or less: twelve participants reported LOQs of $0.5 \mu \mathrm{g} / \mathrm{kg}$, five participants reported LOQs in the range of 0.26 to $0.4 \mu \mathrm{g} / \mathrm{kg}$, six participants reported LOQs in the range of to 0.1 to $0.25 \mu \mathrm{g} / \mathrm{kg}$ and one as low as $0.025 \mu \mathrm{g} / \mathrm{kg}$. Five participants reported LOQs in the range of 0.53 to $1 \mu \mathrm{g} / \mathrm{kg}$ and 4 participants reported LOQs in the range of $2-5 \mu \mathrm{g} / \mathrm{kg}$.

\subsection{Analytical methods}

All participating laboratories were asked to fill in a questionnaire addressing their accreditation, the conditions used for sample preparation, chromatographic separation, detection, quantification and calibration (Annex 8). Three participants did not complete the questionnaire. Two of these participants provided very limited information about the analysis and analytical method via the web application. One participant provided no information at all. The questionnaire of the following participants were submitted after the deadline of October $12^{\text {th }}$ 2020: PT9154-PT9155-PT9156-PT9157-PT9158-PT9161PT9163-PT9165-PT9169-PT9170-PT9171-PT9174-PT9178-PT9180-PT9183-PT9184 and PT9188. Because this could be due to reasons related to COVID-19 it was not evaluated.

Out of 38 laboratories, 12 had their analytical method covered by ISO/IEC 17025:2017 accreditation, while 17 had not accredited their method and nine participants did not provide this information.

Median sample intake reported by the participants was $4 \mathrm{~g}$; the most often reported intake was $2 \mathrm{~g}$ ( 9 participants). Fourteen participants used $2.5 \mathrm{~g}$ or less, 14 participants used between 4 and $10 \mathrm{~g}$, 3 participants used between 20 and $25 \mathrm{~g}$ and seven participants provided no details. The samples were extracted with $25 \mathrm{ml}$ (median volume) of extraction solvent for approximately 30 min (median extraction time). The volumes most often used were $20 \mathrm{ml}(9), 40 \mathrm{ml}(8)$ and $100 \mathrm{ml}$ (5). Most participants (16) reported an extraction time of $30 \mathrm{~min}$; seven participants used an extraction time between 2 and $20 \mathrm{~min}$; 6 participants used an extraction time of $60 \mathrm{~min}$; one participant used $90 \mathrm{~min}$ and 8 participants provided no details. (Aqueous) methanol (21) was used as the extraction solvent by the majority of participants, followed by acidified (aqueous) acetonitrile (ACN) (7). One participant used a mixture of methanol/dichloromethane/ammonia $\left(\mathrm{MeOH} / \mathrm{CH}_{2} \mathrm{Cl}_{2} / \mathrm{NH}_{3}\right.$ ), one used aqueous methanol without the addition of acid, one used pure acetonitrile, one used acetonitrile in combination with an ammoniumhydrogencarbonate $\left(\mathrm{NH}_{4} \mathrm{HCO}_{3}\right)$ buffer, one used acetonitrile with ammonium carbonate $\left.\left(\left(\mathrm{NH}_{4}\right)_{2}\right) \mathrm{CO}_{3}\right)$ buffer, one used acidified water and one participant used the QuEChERS extraction, while three participants did not provide information. Formic acid was most often used (23) as acidifier, followed by sulfuric acid (4) and acetic acid (2). 
Solid phase extraction (SPE) was used by 8 participants for sample extract purification, two participants applied dispersive SPE (d-SPE) of which one used primary secondary amine (PSA). Four participants reported that they diluted the sample extracts, three participants reported that they filtered the extract, one participant reported that the extracts had been frozen for two hours, one participant reported that they used magnesium sulphate $\left(\mathrm{MgSO}_{4}\right)$ and sodium chloride $(\mathrm{NaCl})$ with the extraction, four participants reported that another clean-up was used, 11 participants reported that no clean-up was used and four provided no details on the clean-up used. The following clean-up cartridges were reported: Mycosep (1), Oasis MCX (2), Bond Elut Plexa (2), HF Bond Elut LRC-SCX (1) and Strata-X (1) and one participant did not specify the cartridge they had used.

All participants used liquid chromatography in combination with MS for separation of atropine and scopolamine. Participants used either acetonitrile (20) or methanol (14) as an organic mobile phase modifier. One participant reported only the mobile phase $A$ and three participants did not provide information. The majority of participants (25) indicated that acidic chromatography had been used: 18 participants used formic acid to acidify the mobile phase and six used ammonium formate with addition of formic acid and one used ammonium acetate with addition of formic acid. Nine participants used alkaline chromatography. For the preparation of the alkaline mobile phase the following buffers were used: ammonium carbonate (3), ammonium bicarbonate (1), ammonium hydroxide (2) and ammonia (2). One participant used ammonium hydroxide in combination with ammonium acetate.

A wide variety of columns from different suppliers was used for chromatography with acidic conditions, mostly with C18 based stationary phase: Waters: Acquity UPLC BEH (5), Atlantis T3 (1), HSS T3 (1); Agilent: Zorbax Eclipse Plus (1), Poroshell 120 (1); Phenomenex: Synergi Polar RP (2), Kinetex (3), Luna (1); Thermo Scientific: hypersil Gold (3). In addition, the following non-C18 stationary phase columns were used by number of participants: Supelco: Ascentis Express pentafluorophenyl (4); Phenomenex: Kinetex F5 pentafluorophenyl (2), Kinetex biphenyl (1), Waters: Xbridge BEH amide (1). For alkaline chromatography participants used only $\mathrm{C} 18$ based stationary phase mostly from one supplier Waters: Acquity BEH (4), XBridge (4); Phenomenex: Gemini (1).

LC-MS/MS was used by most participants (34) for the identification and quantification of atropine and scopolamine. One participant used LC-single quadrupole MS and two participants used LC-high resolution mass spectrometry (HRMS). One provided no information.

The quantification approach followed by the participants is summarised in Table 5. Four participants did not indicate what they used as quantification approach. Out of 34 participants, 17 participants used an external standards calibration curve: five prepared the standards in solvent, five prepared the standards in blank matrix extract and seven prepared the calibration standards from a range of spiked blank samples. Seventeen participants used an internal standard addition approach: 7 used single level standard addition to the sample, five used multi-level standard addition to the sample and five used multi-level standard addition to the sample extract. Twenty-eight participants (82\%) have corrected their results for recovery while $18 \%$ reported that they didn't.

Table 5 Analytical strategies followed by the participants.

\begin{tabular}{ccc} 
Quantification approach & No. of participants & Recovery \\
\cline { 2 - 3 } external blank solvent & 5 & 5 \\
\hline external blank extract & 5 & 3 \\
\hline external blank samples & 7 & 5 \\
\hline internal single level to sample & 7 & 7 \\
\hline internal multi-level to sample & 5 & 5 \\
\hline internal multi-level to extract & 5 & 3 \\
\hline
\end{tabular}

Out of 38 participants, twenty-two participants used isotope-labelled internal standards for atropine and scopolamine for quantification. The majority of them added the internal standards before the extraction (19), two added the internal standards to the final extract and one did not indicate when 
the internal standards were added. The first approach provides more benefits as the internal standards can correct the results simultaneously for the losses during the extraction step and compensate the matrix effects during MS analysis.

\subsection{Performance}

The quantitative performance was assessed through z-scores. The individual z-scores obtained by each participant, including their graphical representation, for atropine and scopolamine in materials $A$ (buckwheat flour) and B (maize flour) are summarised in Annex 9 and 10, respectively. A summary of the performance of the participants in this PT is provided in Annex 11.

A summary of the statistical evaluation of the PT results is presented in Table 6. The table includes all relevant parameters: the assigned value $(A)$, the uncertainty of the assigned value $(u)$, the standard deviation for proficiency assessment $\left(\sigma_{p}\right)$ and the robust (relative) standard deviation, based on participants' results.

Table 6 Parameters of the individual tropane alkaloids and summary for materials $A$ and $B$.

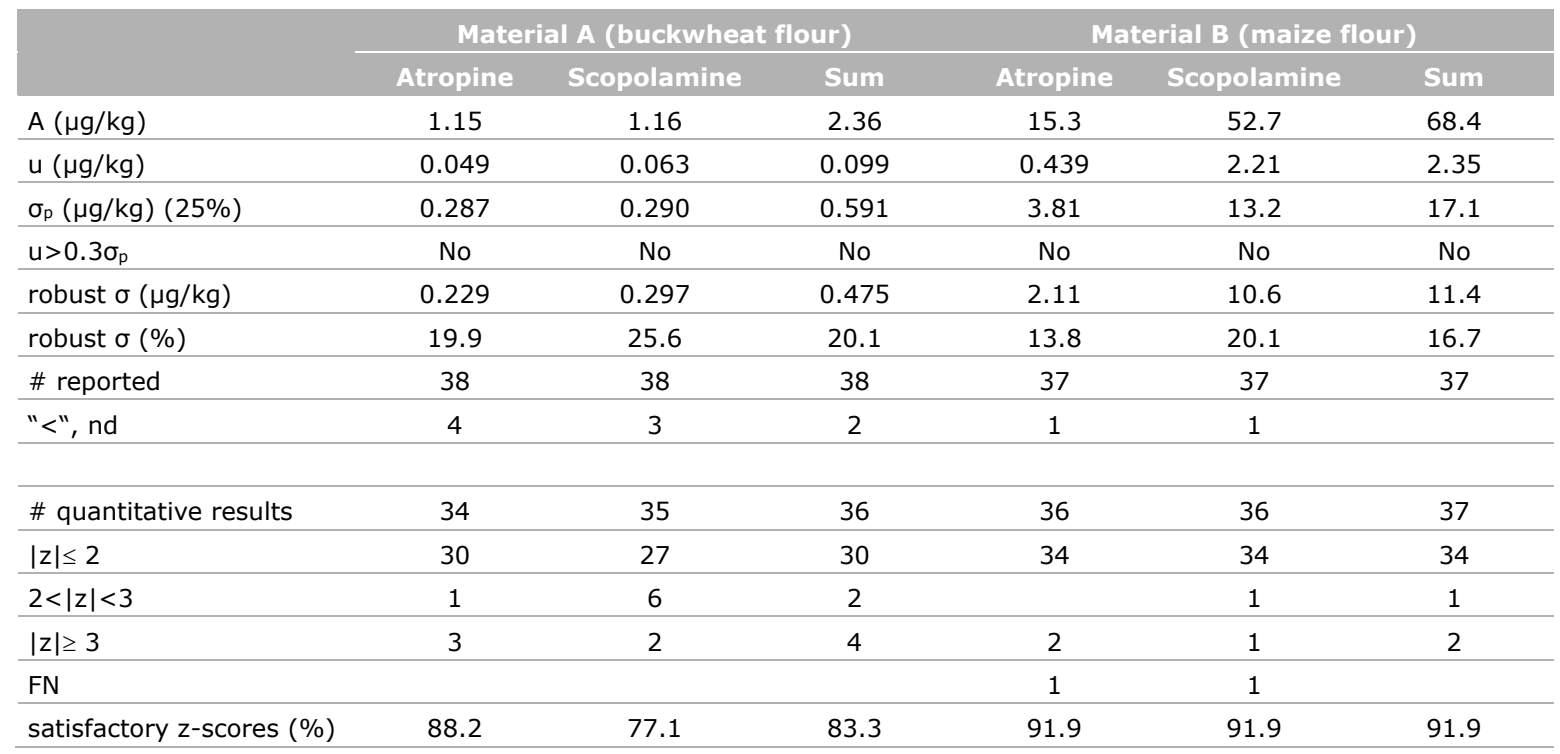

$\mathrm{FN}=$ False negative

nd $=$ not detected

For atropine and scopolamine in both materials, the uncertainty of the assigned value did comply with the criterion $u \leq 0.3 \sigma_{p}$ and was, therefore, considered as negligible in the evaluation of the $z$-scores.

For the individual TAs in material A, 83\% of the results were rated with satisfactory $z$-scores $(|z| \leq 2)$, $10 \%$ of the results fell into the questionable range with $2<|z|<3$ and $7 \%$ of the results fell into the unsatisfactory range with $|z| \geq 3$.

For the individual TAs in material B, $92 \%$ of the results were rated with satisfactory $z$-scores $(|z| \leq 2)$, $1 \%$ of the results fell into the questionable range with $2<|z|<3$ and $7 \%$ of the results fell into the unsatisfactory range with $|z| \geq 3$.

In case of the sum of both TAs, for material A, $83 \%$ of the submitted results were satisfactory and for material B $92 \%$.

Overall, $87 \%$ percent of the atropine and scopolamine results obtained for both materials ( $A$ and $B$ ) were rated with satisfactory $z$-scores $(|z| \leq 2), 6 \%$ of the results fell into the questionable range with $2<|z|<3$ and $7 \%$ of the results fell into the unsatisfactory range with $|z| \geq 3$. 
For material A, four participants reported atropine as not detected or $<\mathrm{LOQ}$ and for scopolamine three participants. Out of these participants the LOQ was in the range 1 to $5 \mu \mathrm{g} / \mathrm{kg}$ while the recommended LOQ for this PT was $0.5 \mu \mathrm{g} / \mathrm{kg}$ or lower. In material B atropine was present at $15.3 \mu \mathrm{g} / \mathrm{kg}$ and scopolamine at $52.7 \mu \mathrm{g} / \mathrm{kg}$. Nevertheless, one participant reported these analytes as below their LOQ. As the proxy z-scores (see 4.4) were $<-2$, these results were classified as false negatives. Besides the false negatives, for atropine in total one questionable and five unsatisfactory results and for scopolamine seven questionable and three unsatisfactory results were observed, mostly for buckwheat flour that contained the lower concentration. The results shows that the laboratories' performance for atropine were slightly better than for scopolamine.

Participant PT9186 reported very high results for material A and did not detect the analytes in material B. Based on the results of participant PT9186, it can be speculated that the samples have been interchanged by the participant.

Participants PT9160, PT9165 and PT9174 reported for material A, one of the two TAs as '<'. For the sum of the TAs, participant PT9160 reported the value for scopolamine $(1.87 \mu \mathrm{g} / \mathrm{kg})$, participant PT9165 reported the sum of the LOQ for atropine and the quantitative result for scopolamine ( $7 \mu \mathrm{g} / \mathrm{kg}$ ) and participant PT9174 reported a sum value of $4.5 \mu \mathrm{g} / \mathrm{kg}$. For material B participant PT9186 reported a sum value of $0.62 \mu \mathrm{g} / \mathrm{kg}$ while reporting both TAs below the LOQ.

In Annex 11 an overview of the overall performance of each participant in this PT is summarised. For the two materials combined, a maximum of 4 satisfactory z-scores could be obtained for the individual TAs, and ' 4 out of 4 ' therefore reflects an optimal performance in terms of scope and capability for quantitative determination. All the participants analysed the materials for atropine and scopolamine. Out of 38 participants, 26 participants achieved optimal performance for both materials by detecting atropine and scopolamine with correct quantification and the absence of false negative results. One participant analysed only material A and achieved optimal performance for that material. For the other 11 participants either the indicated LOQs were too high, false negative results were reported, or one or more non-satisfactory z-scores were obtained.

With respect to the sum of the TAs, 30 participants showed satisfactory performance.

\subsection{Robust relative standard deviation}

The robust relative standard deviation $\left(R_{S D_{R}}\right)$ was calculated according to ISO13528:2015 [12] for informative purposes only. In this study it was used as a good estimation of the interlaboratory variability. The $\mathrm{RSD}_{\mathrm{R}}$ values for atropine and scopolamine in both materials are shown in Annex 9 and 10, in Table 6 (Section 5.3) and also in Table 1 (Summary section).

The robust standard deviation $\left(R S D_{R}\right)$ of the reported results for both TAs are in good agreement with the target standard deviation (25\%). For material $A$, the robust standard deviation for atropine was $20 \%$ and for scopolamine $26 \%$, the latter just above the target standard deviation of $25 \%$. For material $B$, the $\mathrm{RSD}_{\mathrm{R}}$ for both atropine $(14 \%)$ and scopolamine $(20 \%)$ were well below the target standard deviation of $25 \%$ and atropine almost even two times lower. The higher $\mathrm{RSD}_{\mathrm{R}}$ values obtained for material $A$ are most likely related to the lower concentrations of the TAs present in material $A$. The lower $\mathrm{RSD}_{\mathrm{R}}$ for atropine in both materials shows that the laboratories' performance for atropine was slightly better than for scopolamine. The assigned values for both TAs in material A were respectively 1.15 and $1.16 \mu \mathrm{g} / \mathrm{kg}$ and in material $B 15.3$ and $52.7 \mu \mathrm{g} / \mathrm{kg}$.

The $\mathrm{RSD}_{\mathrm{R}}$ values for the sum of TAs are also below the target standard deviation (25\%) for material $A$ $(20 \%)$ as well as material B (17\%). 


\section{Conclusions}

Thirty-eight participants, 29 NRLs (from 22 EU Member States plus Iceland and Norway) and 9 OLs ( 9 from four EU countries and Switzerland) participated in the EURLPT-04 on the quantitative determination of the TAs atropine and scopolamine, in buckwheat flour and maize flour. Both the sample matrices and measurand levels were targeted to provide insight in the capabilities of EU Member States' NRLs concerning the implementation of published legislation in this field (maximum limits of atropine and scopolamine of $1 \mu \mathrm{g} / \mathrm{kg}$, Commission Regulation (EU) 2016/239). In addition to the food product, a maize sample containing a higher level of TAs was included in this PT, since an amendment to the legislation is foreseen.

All laboratories determined both atropine and scopolamine and reported individual levels and the sum.

For individual TAs in material $\mathrm{A}$, the percentage of satisfactory results for atropine was $88 \%$ and for scopolamine $77 \%$. The robust standard deviation $\left(\mathrm{RSD}_{\mathrm{R}}\right)$ of the reported results for atropine $(20 \%)$ was below the target standard deviation (25\%) and for scopolamine (26\%) it was just above the target standard deviation (25\%). The larger variation might be related to the lower concentrations $(1.15 \mu \mathrm{g} / \mathrm{kg}$ for atropine and $1.16 \mu \mathrm{g} / \mathrm{kg}$ for scopolamine) of the individual TAs in this material.

For material B, for both TAs the satisfactory results were $92 \%$ and the $\mathrm{RSD}_{\mathrm{R}}$ were also below the target standard deviation (25\%). One participant did not analyse the TAs in material B.

Overall, for individual TAs in both materials combined, $87 \%$ of the results were rated with satisfactory $z$-scores $(|z| \leq 2), 6 \%$ of the results fell into the questionable range with $2<|z|<3$ and $7 \%$ of the results fell into the unsatisfactory range with $|z| \geq 3$ and 26 participants had a satisfactory performance. In case of the sum of atropine and scopolamine in both materials combined, $88 \%$ of submitted results were satisfactory and 30 participants had a satisfactory performance.

Thirty-four participants used methods based on LC-MS/MS, one used LC-MS and two LC-HRMS, either with or without clean-up. One participant provided no information. Four participants followed the analytical protocol supplied by the EURLMP, while one of them used a different analytical column than the recommended one. The reported LOQs by the participants varied between 0.025 and $5 \mu \mathrm{g} / \mathrm{kg}$. The median LOQs for atropine and scopolamine were both $0.5 \mu \mathrm{g} / \mathrm{kg}$. Since NRLs are expected to have analytical methods in place not only for compliance testing of regulatory limits, but also in the framework of data generation for risk assessment, it is advised to set target LOQs of individual analytes to $0.5 \mu \mathrm{g} / \mathrm{kg}$, at least for cereal-based foods for infants and young children.

Sixty-eight percent of the participants performed satisfactorily for both TAs in buckwheat flour and maize flour and $79 \%$ for the sum of both TAs. Based on the results of this test it is concluded that there is still a need for improvement of the quantification of atropine and scopolamine in buckwheat flour at the levels regulated by the Commission Regulation (EU) 2016/239. 


\section{References}

[1] EFSA, Scientific Opinion on tropane alkaloids in food and feed. EFSA Panel on Contaminants in the Food Chain. EFSA Journal, 2013. 11(10): 3386(10): pp. 113.

[2] European Commission, Commission Regulation (EC) No 1881/2006 of 19 December 2006 setting maximum levels for certain contaminants in foodstuffs. Official Journal of the European Communities, 2006. L364: p. 5-24.

[3] European Commission, Commission Regulation (EU) 2016/239 amending Regulation (EC) No $1881 / 2006$ as regards maximum levels of tropane alkaloids in certain cereal-based foods for infant and young children. Official Journal of the European Union, 2016. L45: p. 3-5.

[4] Analytical Methods Committee. 1989. Robust statistics - How not to reject outliers Part 1. Basic concepts. Analyst 114:1693-1697.

[5] Analytical Methods Committee. 1989. Robust statistics - How not to reject outliers Part 2. Inter-laboratory trials. Analyst. 114:1699-1702.

[6] ISO/IEC 17025:2017(E). 2017. General requirements for the competence of testing and calibration laboratories.

[7] Regulation (EU) $2017 / 625$ on official controls and other official activities performed to ensure the application of food and feed law, rules on animal health and welfare, plant health and plant protection products, Art. 94.2. Off. J. European Union 7.4.2017, L95, p. 1-142.

[8] ISO/IEC 17043:2010. 2010. Conformity assessment - General requirements for proficiency testing.

[9] WFSR SOP-A0989 - Preparation of PT materials and PT samples.

[10] EURLMP-method_004 (version 1), Determination of tropane alkaloids in processed cereal-based foods for infants and young children by LC-MS/MS, WFSR Wageningen University \& Research. https://www.wur.nl/en/show/EURL-MP-Method_004-Tropane-alkaloids-by-LCMSMS_v1.htm

[11] Thompson M, Ellison SL, Wood R. 2006. The International Harmonized Protocol for the Proficiency Testing of Analytical Chemistry Laboratories. Pure Appl. Chem. 78(1):145-196.

[12] ISO 13528:2015. Statistical methods for use in proficiency testing by inter-laboratory comparison, $1^{\text {st }}$ edition. 


\section{Annex 1 List of participants}

\begin{tabular}{|c|c|}
\hline Country & Organisation \\
\hline AUSTRIA* & Institute for Food Safety Innsbruck \\
\hline BELGIUM* & Sciensano \\
\hline CROATIA* & A. Stampar Teaching Institute of Public Health \\
\hline CYPRUS* & State General Laboratory \\
\hline CZECH REPUBLIC* & UKZUZ (Central Institute for Supervising and Testing in Agriculture \\
\hline CZECH REPUBLIC* & Czech Agriculture and Food Inspection Authority (CAFIA) \\
\hline DENMARK* & Danish Veterinary and Food Administration \\
\hline FINLAND* & Finnish Customs Laboratory \\
\hline FINLAND* & Finnish Food Authority \\
\hline FRANCE*** & LABOCEA \\
\hline FRANCE* & Laboratoire SCL de Strasbourg \\
\hline FRANCE* & $\mathrm{SCL}$ \\
\hline GERMANY*** & CVUA-Mel \\
\hline GERMANY*** & Landesbetrieb Hessisches Landeslabor (LHL) \\
\hline GERMANY*** & Bavarian Health and Food Safety Authority \\
\hline GERMANY*** & Chemisches und Veterinaruntersungungsamt (CVUA-RRW) \\
\hline GERMANY** & Eurofins WEJ Contaminants \\
\hline GERMANY* & Federal Institute fur Risk Assessment (BfR) \\
\hline GREECE* & General Chemical State Laboratory \\
\hline HUNGARY* & National Food Chain Safety Office \\
\hline IRELAND* & The State Laboratory \\
\hline IRELAND* & The Public Analyst's Laboratory \\
\hline ITALY* & Istituto Superiore di Sanita \\
\hline LUXEMBOURG* & Laboratoire national de Sante \\
\hline NORWAY** & Norwegian Institute of Bioeconomy Research (NIBIO) \\
\hline POLAND* & National Institute of Public Health - National Institute of Hygiene \\
\hline POLAND*** & Wojewodzka Stacja Sanitarno - Epidemiologiczna w Bydgoszczy \\
\hline POLAND*** & Voivodship Sanitary Epidemiological Station \\
\hline POLAND* & National Veterinary Research Institute \\
\hline ROMANIA* & Institute for Hygiene and Veterinary Public Health \\
\hline SERBIA* & SP Laboratorija A.D. \\
\hline SLOVAKIA* & State veterinary and food institute Dolny Kubin Veterinary and food institute in Kosice \\
\hline SLOVENIA* & National Laboratory of Health, Environment and Food (NLZOH, Slovenia) \\
\hline SPAIN*** & Laboratori Agencia Salut Publica Barcelona \\
\hline SPAIN* & Spanish Agency for Consumer Affairs, Food Safety and Nutrition \\
\hline SWEDEN* & National Food Agency \\
\hline SWITZERLAND*** & Kantonales Laboratorium \\
\hline UNITED KINGDOM* & FERA Science Ltd \\
\hline
\end{tabular}




\section{Annex 2 Codification of the samples}

\begin{tabular}{|c|c|c|}
\hline Participants code & Material A* & Material B* \\
\hline РT9064 & 308 & 315 \\
\hline PT9151 & 151 & 234 \\
\hline PT9152 & 988 & 676 \\
\hline PT9153 & 473 & 734 \\
\hline PT9154 & 522 & 196 \\
\hline PT9155 & 493 & 438 \\
\hline PT9156 & 931 & 829 \\
\hline PT9157 & 116 & 266 \\
\hline PT9158 & 122 & 879 \\
\hline PT9159 & 508 & 157 \\
\hline PT9160 & 408 & 679 \\
\hline PT9161 & 270 & 410 \\
\hline PT9162 & 449 & 221 \\
\hline PT9163 & 749 & 673 \\
\hline PT9164 & 697 & 471 \\
\hline PT9165 & 461 & 633 \\
\hline PT9166 & 173 & 722 \\
\hline PT9167 & 388 & 756 \\
\hline PT9168 & 397 & 571 \\
\hline PT9169 & 446 & 779 \\
\hline PT9170 & 623 & 883 \\
\hline PT9171 & 718 & 945 \\
\hline PT9172 & 675 & 818 \\
\hline PT9173 & 825 & 215 \\
\hline PT9174 & 199 & 403 \\
\hline PT9175 & 325 & 764 \\
\hline PT9176 & 762 & 442 \\
\hline PT9177 & 926 & 469 \\
\hline PT9178 & 606 & 103 \\
\hline PT9179 & 253 & 178 \\
\hline PT9180 & 114 & 262 \\
\hline PT9181 & 184 & 613 \\
\hline PT9182 & 599 & 798 \\
\hline PT9183 & 399 & 766 \\
\hline PT9184 & 171 & 381 \\
\hline PT9185 & 932 & 288 \\
\hline PT9186 & 735 & 572 \\
\hline PT9187 & 791 & 206 \\
\hline PT9188 & 464 & 817 \\
\hline
\end{tabular}

* All sample codes start with 2020/EURLPT MP/TAs/. 


\section{Annex 3 Statistical evaluation of the homogeneity data}

\begin{tabular}{|c|c|c|}
\hline \multirow[b]{2}{*}{ Sample No. } & \multicolumn{2}{|c|}{ Atropine in A $(\mu \mathrm{g} / \mathrm{kg})$} \\
\hline & Replicate 1 & Replicate 2 \\
\hline Hom/A001 & 0.952 & 0.887 \\
\hline Hom/A002 & 0.856 & 0.880 \\
\hline Hom/A003 & 0.904 & 0.878 \\
\hline Hom/A004 & 0.904 & 0.927 \\
\hline Hom/A005 & 0.851 & 0.854 \\
\hline Hom/A006 & 0.857 & 0.882 \\
\hline Hom/A007 & 0.785 & 0.868 \\
\hline Hom/A008 & 0.845 & 0.897 \\
\hline Hom/A009 & 0.891 & 0.911 \\
\hline Hom/A010 & 0.914 & 0.896 \\
\hline Grand mean & \multicolumn{2}{|c|}{0.882} \\
\hline \multicolumn{3}{|l|}{ Cochran's test } \\
\hline $\mathrm{C}$ & \multicolumn{2}{|c|}{0.400} \\
\hline Ccrit & \multicolumn{2}{|c|}{0.602} \\
\hline$C<$ Ccrit? & \multicolumn{2}{|c|}{ NO OUTLIERS } \\
\hline Target $\mathrm{s}=\sigma_{\mathrm{p}}$ & \multicolumn{2}{|c|}{0.220} \\
\hline $\mathrm{s}_{\mathrm{x}}$ & \multicolumn{2}{|c|}{0.030} \\
\hline $\mathrm{S}_{w}$ & \multicolumn{2}{|c|}{0.029} \\
\hline $\mathrm{S}_{\mathrm{s}}$ & \multicolumn{2}{|c|}{0.021} \\
\hline Critical $=0.3 \sigma_{\mathrm{p}}$ & \multicolumn{2}{|c|}{0.058} \\
\hline $\mathrm{S}_{\mathrm{s}}<$ critical? & \multicolumn{2}{|c|}{ ACCEPTED } \\
\hline $\mathrm{S}_{\mathrm{w}}<0.5 \sigma_{\mathrm{p}} ?$ & \multicolumn{2}{|c|}{ ACCEPTED } \\
\hline
\end{tabular}

Sample No

Hom/A001

Hom/A002

$\mathrm{Hom} / \mathrm{A003}$

Hom/A004

Hom/A005

Hom/A006

Hom/A007

Hom/A008

Hom/A009

Hom/A010

Grand mean

Cochran's test

$$
\text { C }
$$

Ccrit

$\mathrm{C}<$ Ccrit?

Target $s=\sigma_{p}$

$\mathrm{S}_{\mathrm{x}}$

Sw

$\mathrm{s}_{\mathrm{s}}$

Critical $=0.3 \sigma_{\mathrm{P}}$

$\mathrm{S}_{\mathrm{s}}<$ critical?

$\mathrm{S}_{\mathrm{w}}<0.5 \sigma_{\mathrm{p}}$ ?

$s_{\mathrm{X}}=$ Standard deviation of the sample averages.

$S_{w}=$ Within-sample standard deviation.

$\mathrm{s}_{\mathrm{s}}=$ Between-sample standard deviation.

\section{Scopolamine in A $(\mu \mathrm{rg} / \mathrm{kg})$}

$\begin{array}{ccc}\text { Replicate } 1 & & \text { Replicate 2 } \\ 0.977 & & 0.944 \\ 0.892 & & 0.964 \\ 0.894 & & 0.954 \\ 0.921 & & 0.934 \\ 0.818 & & 0.941 \\ 0.921 & & 0.897 \\ 0.819 & & 0.918 \\ 0.947 & & 0.910 \\ 0.966 & & 0.912 \\ 1.028 & & 1.004 \\ & 0.928 & \\ & 0.374 & \\ & 0.602 & \\ & \text { NO OUTLIERS } \\ & 0.23 & \\ & 0.041 \\ & 0.045 & \\ & 0.026 \\ & 0.061 & \\ & \text { ACCEPTED } \\ & \text { ACCEPTED } \\ \end{array}$




\begin{tabular}{|c|c|c|}
\hline \multirow[b]{2}{*}{ Sample No. } & \multicolumn{2}{|c|}{ Atropine in B $(\mu \mathrm{g} / \mathrm{kg})$} \\
\hline & Replicate 1 & Replicate 2 \\
\hline Hom/B001 & 13.5 & 13.7 \\
\hline Hom/B002 & 13.4 & 14.2 \\
\hline Hom/B003 & 13.8 & 13.5 \\
\hline Hom/B004 & 13.7 & 13.9 \\
\hline Hom/B005 & 13.7 & 13.6 \\
\hline Hom/B006 & 14.1 & 14.1 \\
\hline Hom/B007 & 13.7 & 13.9 \\
\hline Hom/B008 & 13.7 & 13.6 \\
\hline Hom/B009 & 13.6 & 13.6 \\
\hline Hom/B010 & 13.4 & 14.0 \\
\hline Grand mean & \multicolumn{2}{|c|}{13.7} \\
\hline \multicolumn{3}{|l|}{ Cochran's test } \\
\hline $\mathrm{C}$ & \multicolumn{2}{|c|}{0.542} \\
\hline Ccrit & \multicolumn{2}{|c|}{0.602} \\
\hline$C<$ Ccrit? & \multicolumn{2}{|c|}{ NO OUTLIERS } \\
\hline Target $\mathrm{s}=\sigma_{\mathrm{P}}$ & \multicolumn{2}{|c|}{3.43} \\
\hline$s_{x}$ & \multicolumn{2}{|c|}{0.144} \\
\hline $\mathrm{S}_{\mathrm{w}}$ & \multicolumn{2}{|c|}{0.258} \\
\hline $\mathrm{S}_{\mathrm{s}}$ & \multicolumn{2}{|c|}{0.000} \\
\hline Critical $=0.3 \sigma_{p}$ & \multicolumn{2}{|c|}{0.907} \\
\hline $\mathrm{S}_{\mathrm{s}}<$ critical? & \multicolumn{2}{|c|}{ ACCEPTED } \\
\hline $\mathrm{S}_{\mathrm{w}}<0.5 \sigma_{\mathrm{p}} ?$ & \multicolumn{2}{|c|}{ ACCEPTED } \\
\hline
\end{tabular}

$\mathrm{S}_{\mathrm{x}}=$ Standard deviation of the sample averages.

$\mathrm{S}_{\mathrm{w}}=$ Within-sample standard deviation.

$\mathrm{s}_{\mathrm{s}}=$ Between-sample standard deviation.

Scopolamine in B $(\mu \mathrm{g} / \mathrm{kg})$

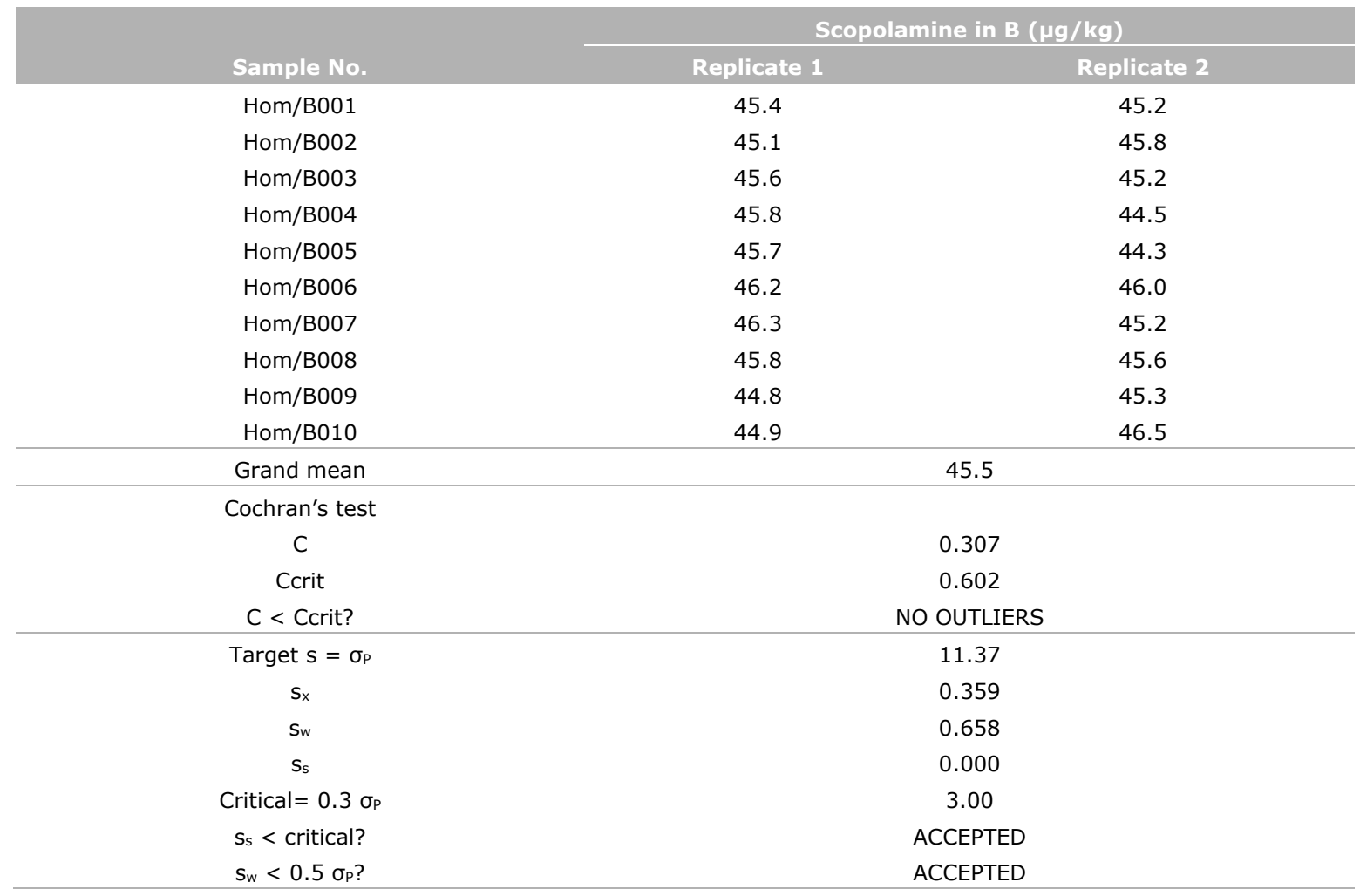

$\mathrm{s}_{\mathrm{x}}=$ Standard deviation of the sample averages.

$\mathrm{S}_{\mathrm{w}}=$ Within-sample standard deviation.

$\mathrm{S}_{\mathrm{s}}=$ Between-sample standard deviation. 


\section{Annex 4 Statistical evaluation of the stability data}

Stability evaluation for atropine in material A

\begin{tabular}{ccc} 
Storage temperature & $<-20{ }^{\circ} \mathrm{C}$ & $<{ }^{\circ} \mathrm{C}$ \\
Time (days) & 0 & 70 \\
\hline Calculated amounts $(\mu \mathrm{g} / \mathrm{kg})$ & 1.14 & 1.08 \\
& 1.15 & 1.08 \\
& 1.02 & 0.913 \\
& 0.990 & 1.00 \\
Average amount $(\mu \mathrm{g} / \mathrm{kg})$ & 0.930 & 0.962 \\
$\mathrm{n}$ & 1.05 & 1.00 \\
st. dev $(\mu \mathrm{g} / \mathrm{kg})$ & 1.047 & 6 \\
Difference & 6 & 0.066 \\
$0.3^{*} \sigma_{\mathrm{P}}$ & 0.086 & 0.040 \\
\hline Consequential difference? Diff $<0.3^{*} \sigma_{\mathrm{P}}$ & & 0.079 \\
\end{tabular}

Stability evaluation for scopolamine in material A

\begin{tabular}{ccc} 
Storage temperature & $<-20{ }^{\circ} \mathrm{C}$ & $<{ }^{\circ} \mathrm{C}$ \\
Time (days) & 0 & 70 \\
\hline Calculated amounts $(\mu \mathrm{g} / \mathrm{kg})$ & 1.11 & 1.06 \\
& 1.08 & 1.06 \\
& 1.08 & 0.99 \\
& 1.06 & 1.12 \\
Average amount $(\mu \mathrm{g} / \mathrm{kg})$ & 1.14 & 0.982 \\
$\mathrm{n}$ & 0.979 & 1.03 \\
st. dev $(\mu \mathrm{g} / \mathrm{kg})$ & 1.08 & 6 \\
Difference & 6 & 0.052 \\
$0.3 * \sigma_{p}$ & 0.053 & 0.040 \\
\hline Consequential difference? Diff $<0.3 * \sigma_{p}$ & & 0.081 \\
\end{tabular}

Stability evaluation for atropine in material B

\begin{tabular}{|c|c|c|}
\hline Storage temperature & $<-20^{\circ} \mathrm{C}$ & $<4^{\circ} \mathrm{C}$ \\
\hline Time (days) & 0 & 70 \\
\hline \multirow[t]{4}{*}{ Calculated amounts $(\mu \mathrm{g} / \mathrm{kg})$} & 13.3 & 13.4 \\
\hline & 13.2 & 14.4 \\
\hline & 13.3 & 13.8 \\
\hline & 13.7 & 13.4 \\
\hline Average amount $(\mu \mathrm{g} / \mathrm{kg})$ & 13.3 & 13.7 \\
\hline $\mathrm{n}$ & 6 & 6 \\
\hline st. dev $(\mu \mathrm{g} / \mathrm{kg})$ & 0.229 & 0.369 \\
\hline Difference & & -0.357 \\
\hline
\end{tabular}




\section{Stability evaluation for scopolamine in material B}

\begin{tabular}{|c|c|c|}
\hline Storage temperature & $<-20^{\circ} \mathrm{C}$ & $<4^{\circ} \mathrm{C}$ \\
\hline \multirow[t]{4}{*}{ Calculated amounts $(\mu \mathrm{g} / \mathrm{kg})$} & 47.4 & 49.2 \\
\hline & 44.9 & 48.0 \\
\hline & 47.4 & 49.1 \\
\hline & 46.1 & 48.9 \\
\hline Average amount $(\mu \mathrm{g} / \mathrm{kg})$ & 47.1 & 48.1 \\
\hline $\mathrm{n}$ & 6 & 6 \\
\hline st. $\operatorname{dev}(\mu \mathrm{g} / \mathrm{kg})$ & 1.43 & 1.44 \\
\hline Difference & & -0.965 \\
\hline
\end{tabular}




\section{Annex 5 Invitation letter}

WAGENINGEN

UNIVERSITY Q RESEARCH

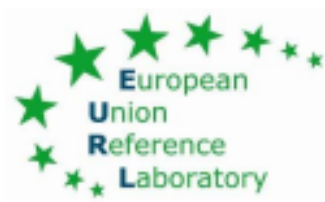

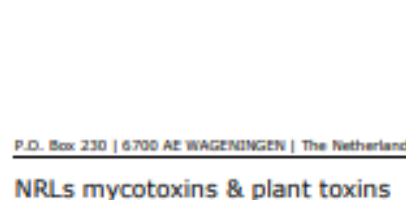

Wageningen Food

Safety Research

antin

June 30,2020

Invitation EURL mycotoxins s

plant toxins proficiency test

tropane alkaloids in food and

Dear colleague,

P.O. Box 230

6700 AE WAGENINGEN

The Netherlands

The EURL mycotoxins \& plant toxins, at Wageningen Food Safety Research (WFSR), will organize a proficiency test (PT) regarding tropane alkaloids in food and feed matrices (EURLPT-MP04). This test will focus on the quantification of the tropane alkaloids atropine and scopolamine and will be organised under accreditation according to ISO 17043 (General requirements for proficiency testing - R013). Harmonised EU regulation for atropine and scopolamine in these matrices is being prepared and their inclusion in national monitoring is recommended by EFSA.

This PT will focus on quantification of atropine and scopolamine considered for legislation in food and feed products. The primary goal of this proficiency test is to give laboratories the opportunity to evaluate or demonstrate their performance regarding the analysis of these compounds in food and feed matrices.

According to Regulation (EU) 2017/625 all EU National Reference Laboratories (NRLs) mycotoxins \& plant toxins in food and/or feed are mandatory to participate. I would like to invite you to participate in this PT.

1. Test materials

One test sample of maize four and one test sample of buckwheat flour will be provided. The test materials maize flour and buckwheat flour are representatives for food and feed. The test amount sent will be approximately $50 \mathrm{~g}$.

2. Shipment of test materials

Test materials will be sent in the last week of August 2020. The distribution of the test materials will be announced by e-mail. The deadline for reporting is strict and will be six weeks after the date of shipment of the samples.

3. Scope of analysis

The materials contain the following analytes:

- Atropine

- Scopolamine

Minimal LOQ $0.5 \mu \mathrm{g} / \mathrm{kg}$.

vartoer necouss

Wageningen Campus

Building 123

6708 WB WAGENINGEN

monean

www.wur.nl/west

oct neveik

05098104

Diana Pereboom

numone

$+31(0) 614323017$

ames.

pt.wtsrowur.net 
4. Questionnaire

A questionnaire will be sent electronically. In this questionnaire the particants will be asked to provide information about the laboratory method used. This information is necessary to conduct a more in depth analysis of the results obtained in this proficiency test.

5. Report

- A report of the proficiency test will be dispatched early in 2021

- Results of the proficiency test will be presented anonymously

- The follow-up protocol on proficiency test from DG Santé will be applied

6. Additional information

- WFSR is allowed to use the anonymous results of the proficiency test in presentations, seminars and publications

- WFSR will never inform third parties (e.g. accreditation bodies) on specific laboratory results without informing the laboratory first

7. Costs

- Participation is free of charge for the NRLs.

- Official laboratories (OLs) can participate as long as sufficient test material is available, at a first come first serve basis. The participation fee is $€ 270$, - (ex. VAT) as a compensation for the preparation and transportation of the samples.

- If an extra batch of samples is needed after the first shipping, the courier costs will be charged.

If you would like to participate, please fill out the accompanying participation form (preferably digitally) and send it back before the $24^{\text {th }}$ of July 2020 to:

pt.wfsr(a)wur.nl.

Looking forward to welcome you for this test,

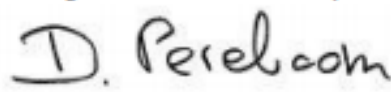

Diana Pereboom-de Fauw

Proficiency tests

EURL mycotoxins \& plant toxins

Wageningen Food Safety Research

Wageningen

The Netherlands 


\section{Annex 6 Instruction letter}

WAGENINGEN

UNIVERSITY \& RESERRCH

Dear Madam, Sir,

Thank you very much for your participation in the proficiency test for the analysis of tropane alkaloids in food and feed matrices.

The parcel shipped to you should contain:

One feed material consisting of maize flour and one food material consisting of buckwheat flour. Each test material unit contains approximately 50 grams of the homogenised test material.

\section{Instructions:}

After arrival the samples should be stored at $+4{ }^{\circ} \mathrm{C}$.

Please fill in the accompanied 'acknowledgement of receipt form' and return it immediately upon receipt of the samples by e-mail to pt.wfsniawur.n. Before analysis, homogenise the samples according to your laboratory's procedure.

Treat the test material as a sample for routine analysis. Report one result and not an average of multiple measurements.

The tropane alkaloids atropine and scopolamine are considered for legislation in food products. The concentrations of atropine and scopolamine should be reported individually and as a sum of atropine and scopolamine.

Please report all analytical results in $\mu g / \mathrm{kg}$. If an analyte is not included in the scope of the method, please report 'nt (not tested)' in the corresponding place of the web application. When the result for an analyte is below your LOQ, 'please report the result as ' $\angle$ LOQ-value' and specify the value (e.g. $<10 \mu \mathrm{g} / \mathrm{kg}$ ). Do not report these results as 'not detected'. Please note that the recommended LOQ for this proficiency test is $0.5 \mu \mathrm{g} / \mathrm{kg}$ or lower. Please use the following web application for entering your results for the test samples (https://crlwebshop.wur.nl/apex/f? $\mathrm{p}=107:$ LOGIN). Instructions for use of this web application were sent to you earlier by e-mail. If you didn't receive these instructions or you have a question, please contact us. Provide detailed information in the questionnaire on the analysis of the tropane alkaloids and the analytical method used and send it back to us by e-mail (pt.wfsriawur.nl).

Wageningen Food

Safety Research

August 31, 2020

Instructions profidiency test trogane alkaloids in food and foed matrices

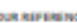

2023291/WFSR

P.O. Box 230

6700 AE WAGENINGEN

The Netherfands

vartoer necous:

Wageningen Campus

Building 123

Akkermaalsbes 2

6708 WB WAGENINGEN

www.mur.nl

09098104

unsuse

D.P.K.H. Pereboom - de Faun

Thenconi

$+31(0) 614323017$

ames

ptrikitemur.nel 


\section{ann \\ August 25, 2020 \\ Gos nurveanca \\ 2023291/WF5R \\ $\operatorname{mis}$}

You can download the EURL method "EURL-MP-method-004 Determination of tropane alkaloids in processed cereal-based foods for infants and young children by LC-MS/MS, for the analysis of tropane alkaloids using LC-MS/MS", from the EURL mycotoxins \& plant toxins website:

(https://www.wur.nl/en/Research-Results/Research-Institutes/food-safetyresearch/Reference-laboratory/European-Union-Reference-Laboratory1/EURL-mycotoxins-plant-toxins/Library-EURL-MP.htm).

- The deadline for submitting test-results for this test is the $\mathbf{1 2}^{\text {th }}$ of October, 2020. Please note that this will be a strict deadline; results reported after the deadline will not be considered. The EURL should be contacted at least 2 weeks in advance, if for exceptional reasons the deadline cannot be met.

- Your username is:

- Your password is:

- Your lab code to enter this proficiency test is:

Please contact me in case you have any questions or need any assistance.

With kind regards,

$$
\text { D. Pereloom }
$$

Diana Pereboom

Proficiency tests

EURL mycotoxins \& plant toxins

Wageningen Food Safety Research (WFSR)

The Netherlands 


\section{Annex 7 Scope and LOQ}

\begin{tabular}{|c|c|c|}
\hline & Atropine & Scopolamine \\
\hline Lab code & \multicolumn{2}{|c|}{ LOQ ( $\mu \mathrm{g} / \mathrm{kg})$} \\
\hline PT9064 & 0.5 & 0.5 \\
\hline PT9152 & 0.5 & 0.5 \\
\hline PT9153 & 0.5 & 0.5 \\
\hline \multicolumn{3}{|l|}{ PT9154 } \\
\hline \multicolumn{3}{|l|}{ PT9155 } \\
\hline PT9156 & 0.4 & 0.4 \\
\hline \multicolumn{3}{|l|}{ PT9157 } \\
\hline \multicolumn{3}{|l|}{ PT9158 } \\
\hline PT9159 & 0.1 & 0.1 \\
\hline PT9160 & 1 & 1 \\
\hline PT9161 & 0.4 & 0.4 \\
\hline PT9162 & 5 & 5 \\
\hline PT9163 & 0.72 & 0.72 \\
\hline PT9164 & 0.8 & 0.8 \\
\hline \multicolumn{3}{|l|}{ PT9165 } \\
\hline PT9166 & 0.025 & 0.05 \\
\hline PT9167 & 0.2 & 0.2 \\
\hline PT9168 & 0.53 & 0.52 \\
\hline PT9169 & 0.25 & 0.25 \\
\hline PT9170 & 0.5 & 0.5 \\
\hline PT9171 & 5 & 5 \\
\hline PT9172 & 0.26 & 0.27 \\
\hline PT9173 & 0.3 & 0.3 \\
\hline PT9174 & 2 & 2 \\
\hline PT9175 & 0.2 & 0.2 \\
\hline PT9176 & 1 & 1 \\
\hline PT9177 & 0.5 & 0.5 \\
\hline PT9178 & 0.5 & 0.5 \\
\hline PT9179 & 0.5 & 0.5 \\
\hline PT9180 & 0.40 & 0.36 \\
\hline PT9181 & 0.25 & 0.25 \\
\hline PT9182 & 0.5 & 0.5 \\
\hline PT9183 & 0.5 & 0.5 \\
\hline PT9184 & 0.1 & 0.1 \\
\hline PT9185 & 0.5 & 0.5 \\
\hline PT9186 & 0.5 & 0.5 \\
\hline PT9187 & 0.5 & 0.5 \\
\hline PT9188 & 5 & 5 \\
\hline
\end{tabular}




\section{Annex 8 Method details}

\begin{tabular}{|c|c|c|c|c|c|c|c|c|}
\hline Lab code & Method & Column & $\begin{array}{l}\text { Column } \\
\text { length } \\
(\mathrm{mm})\end{array}$ & $\begin{array}{l}\text { Total run } \\
\text { time } \\
\text { ( } \mathrm{min})\end{array}$ & Mobile phase & $\begin{array}{l}\text { Detection } \\
\text { technique }\end{array}$ & RT (min) & RT (min) \\
\hline PT9064 & acid & Supelco Ascentis express F5, $100 \times 2.1 \mathrm{~mm}, 2.7 \mu \mathrm{m}$ & 100 & 16 & & HRMS & 3.62 & 2.95 \\
\hline PT9152 & acid & Waters Atlantis T3, $150 \times 3.0 \mathrm{~mm}, 3 \mu \mathrm{m}$ & 150 & 22 & $\begin{array}{c}\text { A: } 95+5 \mathrm{MeOH} / \mathrm{H}_{2} \mathrm{O} v / \mathrm{v}+1 \% \mathrm{FA}+5 \mathrm{mM} \mathrm{HCOONH}_{4} ; \\
\text { B: } \mathrm{H}_{2} \mathrm{O}+1 \% \mathrm{FA}+5 \mathrm{mM} \mathrm{HCOONH}_{4}\end{array}$ & MS/MS & 9.7 & 8.8 \\
\hline PT9153 & acid & Phenomenex Luna C18, $100 \times 2 \mathrm{~mm}$ & 100 & 13 & $\mathrm{~A}$ and $\mathrm{B}: 5 \mathrm{mM}$ AmAc/ACN/formic acid & MS/MS & 6.5 & 6.2 \\
\hline PT9154 & & & & & & MS/MS & & \\
\hline PT9155 & acid & Phenomenex Kinetex F5, 100 × 2.1 mm, $2.6 \mu \mathrm{m}$ & 100 & & A: $\mathrm{H}_{2} \mathrm{O}+0.1 \%$ formic acid; $\mathrm{B}: \mathrm{ACN}+0.1 \%$ formic acid & MS/MS & & \\
\hline PT9156 & acid & Supelco Ascentis Express F5, $100 \times 2.1 \mathrm{~mm}, 2.7 \mu \mathrm{m}$ & 100 & 13 & A: $\mathrm{H}_{2} \mathrm{O}+0.1 \% \mathrm{HCOOH} ; \mathrm{B}: \mathrm{ACN}+0.1 \% \mathrm{HCOOH}$ & MS/MS & 6.74 & 5.59 \\
\hline PT9157 & alkaline & Waters UPLC BEH C18, $100 \times 2.1 \mathrm{~mm}$ & 100 & 10 & $\begin{array}{l}\text { A: Ammoniumhydrogencarbonate } 10 \mathrm{mM} \text {; } \\
\text { B: } \mathrm{ACN}+10 \mathrm{mM} \text { Ammoniumhydrogencarbonate }\end{array}$ & MS/MS & & \\
\hline PT9158 & & & & & & UPLC/MS/MS & & \\
\hline PT9159 & acid & Agilent Poroshell 120 EC-C18, $100 \times 4.6 \mathrm{~mm}, 2.7 \mu \mathrm{m}$ & 100 & 12 & A: $0.2 \%$ formic acid in $\mathrm{H}_{2} \mathrm{O}$; B: $0.2 \%$ formic acid in $\mathrm{MeOH}$ & MS/MS & 9.17 & 5.58 \\
\hline PT9160 & acid & Waters Acquity UPLC BEH, C18, $50 \times 2.1 \mathrm{~mm}, 1.7 \mu \mathrm{m}$ & 50 & 15 & $0.1 \%$ formic acid in $\mathrm{H}_{2} \mathrm{O} / 0.1 \%$ formic acid in $\mathrm{MeOH}$ & MS/MS & 4.8 & 2.5 \\
\hline PT9161 & acid & Waters Xbridge Amide, $150 \times 2.1 \mathrm{~mm}, 3.5 \mu \mathrm{m}$ & 150 & 20 & A: $0.05 \%$ formic acid in $\mathrm{H}_{2} \mathrm{O}$; B: $\mathrm{ACN}$ & MS/MS & 2.56 & 2.69 \\
\hline PT9162 & acid & Waters Acquity UPLC BEH C18, $100 \times 2.1 \mathrm{~mm}, 1.7 \mu \mathrm{m}$ & 100 & 10 & A: $\mathrm{H}_{2} \mathrm{O}+0.1 \% \mathrm{HCOOH} ; \mathrm{B}: \mathrm{MeOH}+0.1 \% \mathrm{HCOOH}+1 \mathrm{mM} \mathrm{HCOONH}_{4}$ & MS/MS & 1.336 & 1.174 \\
\hline PT9163 & acid & Phenomenex Biphenyl, $100 \times 2.1 \mathrm{~mm}, 2.6 \mu \mathrm{m}$ & 100 & 10 & $A: \mathrm{H}_{2} \mathrm{O}+0.1 \%$ formic acid; $\mathrm{B}: \mathrm{ACN}+0.1 \%$ formic acid & MS/MS & 7.1 & 6.9 \\
\hline PT9164 & acid & Phenomenex Synergi Polar RP, $100 \times 2 \mathrm{~mm}, 80 \AA, 4 \mu \mathrm{m}$ & 100 & 9.1 & $A: \mathrm{H}_{2} \mathrm{O}+0.1 \%$ formic acid; $\mathrm{B}: \mathrm{ACN}+0.1 \%$ formic acid & MS/MS & 4.5 & 3.5 \\
\hline \multicolumn{9}{|l|}{ PT9165 } \\
\hline PT9166 & acid & $\begin{array}{l}\text { Thermo Scientific, Hypersil Gold C18, } 200 \times 2.1 \mathrm{~mm}, 1.9 \\
\qquad \mu \mathrm{m}\end{array}$ & 200 & 26 & $\begin{array}{l}\text { A: } \mathrm{H}_{2} \mathrm{O}, \mathrm{HCOOH} 0.1 \%, \mathrm{HCOONH}_{4}+: 315 \mathrm{mg} / \mathrm{L} ; \\
\text { B: } \mathrm{MeOH}, \mathrm{HCOOH} 0.1 \%, \mathrm{HCOONH}_{4}+: 315 \mathrm{mg} / \mathrm{L}\end{array}$ & MS/MS & 10.56 & 8.59 \\
\hline PT9167 & acid & Phenomenex, Kinetex C18, $100 \times 2.1 \mathrm{~mm}, 2.6 \mu \mathrm{m}$ & 100 & 45 & $\begin{array}{c}\text { A: } 5 \mathrm{mmol} \text { ammonium formiate and } 1 \mathrm{ml} \text { formic acid in } 1000 \mathrm{ml} \mathrm{H}_{2} \mathrm{O} \text {; } \\
\text { B: } 5 \mathrm{mmol} \text { ammonium formiate and } 1 \mathrm{ml} \text { formic acid in } 1000 \mathrm{ml} \\
\text { MeOH }\end{array}$ & MS/MS & 16.44 & 10.82 \\
\hline PT9168 & acid & Phenomenex Synergi Polar-RP $50 \times 2 \mathrm{~mm}, 2.5 \mu \mathrm{m}$ & 50 & 16 & A: $0.1 \% \mathrm{HCOOH}(\mathrm{aq}) ; \mathrm{B}: 0.1 \% \mathrm{HCOOH}(\mathrm{MeOH})$ & MS/MS & 2.4 & 1.9 \\
\hline PT9169 & alkaline & Waters UPLC BEH C $18,150 \times 2.1 \mathrm{~mm}, 1.7 \mu \mathrm{m}$ & 150 & & A: $10 \mathrm{mM}$ ammonium carbonate; B: ACN & MS/MS & 8.63 & 7.47 \\
\hline PT9170 & alkaline & Waters Xbridge $\mathrm{C} 18,75 \times 3 \mathrm{~mm}$ & 75 & 12 & A: $6 \mathrm{mM} \mathrm{NH}_{4} \mathrm{OH} ; \mathrm{B}: \mathrm{MeOH} / 6 \mathrm{mM} \mathrm{NH}{ }_{4} \mathrm{OH}$ & MS/MS & 6.8 & 5.8 \\
\hline PT9171 & acid & Thermo Hypersil Gold aQ & & 6 & A: $\mathrm{H}_{2} \mathrm{O}$ /formic acid; $\mathrm{B}: \mathrm{MeOH}$ & MS/MS & 3.7 & 3.6 \\
\hline
\end{tabular}




\begin{tabular}{|c|c|c|c|c|c|c|c|c|}
\hline Lab code & Method & Column & $\begin{array}{l}\text { Column } \\
\text { length } \\
(\mathrm{mm})\end{array}$ & $\begin{array}{c}\text { Total run } \\
\text { time } \\
\text { (min) }\end{array}$ & Mobile phase & $\begin{array}{l}\text { Detection } \\
\text { technique }\end{array}$ & $\begin{array}{l}\text { Atropine } \\
\text { RT (min) }\end{array}$ & $\begin{array}{l}\text { Scopolamine } \\
\text { RT (min) }\end{array}$ \\
\hline PT9172 & acid & Supelco Ascentis Express F5, $100 \times 2.1 \mathrm{~mm}, 2.7 \mu \mathrm{m}$ & 100 & 16 & A: $\mathrm{H}_{2} \mathrm{O}+0.1 \%$ formic acid; $\mathrm{B}: \mathrm{ACN}+0.1 \%$ formic acid & MS/MS & 2.88 & 2.28 \\
\hline PT9173 & alkaline & Phenomenex Gemini C18, $100 \times 2.0$ mm, $3 \mu \mathrm{m}$ & 100 & 11 & A: $M Q-\mathrm{H}_{2} \mathrm{O}$ with $\mathrm{NH}_{3}\left(\mathrm{pH}\right.$ 10.7); B: ACN with $\mathrm{NH}_{3}$ & HRMS & 4.07 & 3.15 \\
\hline PT9174 & acid & $\begin{array}{l}\text { Agilent Zorbax Eclipse Plus C18 RRHD, } 50 \times 2.1 \mathrm{~mm}, 1.8 \\
\qquad \mathrm{~m}\end{array}$ & 50 & 27 & A: $10 \mathrm{mM}$ ammoniumformiate; $\mathrm{B}: 0.2 \%$ formic acid in $\mathrm{MeOH}$ & MS/MS & 4.1 & 2.7 \\
\hline PT9175 & acid & Waters HSS T3, $100 \times 2.1 \mathrm{~mm}, 1.7 \mu \mathrm{m}$ & 100 & 22 & A: $\mathrm{H}_{2} \mathrm{O}, 5 \mathrm{mM}$ ammonium acetate, $0.1 \%$ acetic acid & MS/MS & 3 & 2.5 \\
\hline PT9176 & alkaline & Waters Xbridge $\mathrm{C} 18,150 \times 3 \mathrm{~mm}, 5 \mu \mathrm{m}$ & 150 & 20 & A: Ammonium carbonate $0.2 \mathrm{~g} / \mathrm{l} ; \mathrm{B}: \mathrm{ACN}$ & MS/MS & 5.7 & 4.7 \\
\hline PT9177 & acid & Phenomenex Kinetex $\mathrm{C} 18,150 \times 4.6 \mathrm{~mm} ; 2.6 \mu \mathrm{m}, 100 \AA$ & 150 & 12 & A: $0.2 \% \mathrm{HCOOH} / \mathrm{H}_{2} \mathrm{O} ; \mathrm{B}: \mathrm{MeOH}$ & MS/MS & 6.94 & 6.1 \\
\hline PT9178 & alkaline & Waters Acquity UPLC BEH C18, $150 \times 2.1 \mathrm{~mm}, 1.7 \mu \mathrm{m}$ & 150 & 21 & A: $10 \mathrm{mM}$ ammonium carbonate in $\mathrm{H}_{2} \mathrm{O} \mathrm{pH}$ 9.0; $\mathrm{B}$ : $\mathrm{ACN}$ & MS/MS & 11.08 & 11.29 \\
\hline PT9179 & acid & Phenomenex Kinetex, C18, $100 \times 4.6$ mm; $2.6 \mu \mathrm{m}$ & 100 & 10.5 & A: $0.3 \%$ formic acid in $\mathrm{H}_{2} \mathrm{O}$; $\mathrm{B}: \mathrm{MeOH}$ & MS (single) & 7.2 & 6 \\
\hline PT9180 & alkaline & Waters Xbridge $\mathrm{C} 18,150 \times 3 \mathrm{~mm}, 5 \mu \mathrm{m}$ & 150 & 25 & A: ammonia $6 \mathrm{mM}$ in $\mathrm{H}_{2} \mathrm{O}$; $\mathrm{B}$ : ammonia $6 \mathrm{mM}$ in $\mathrm{ACN}$ & MS/MS & 8.7 & 6.8 \\
\hline PT9181 & acid & Thermo Hypersil GOLD C18, $150 \mathrm{~mm} \times 2.1 \mathrm{~mm}, 1.9 \mu \mathrm{m}$ & 150 & 15 & $\begin{array}{l}\text { A: } 5 \mathrm{mmol} \text { Ammoniumformate }+0.1 \% \text { Formic Acid in } \mathrm{H}_{2} \mathrm{O} \text {; } \\
\text { B: } 5 \mathrm{mmol} \text { Ammoniumformate }+0.1 \% \text { Formic Acid in } 95 \% \mathrm{MeOH}\end{array}$ & MS/MS & 6.2 & 5.1 \\
\hline PT9182 & acid & Supelco Ascentis Express F5 & & 10 & A: $98 \% \mathrm{H}_{2} \mathrm{O}+0.1 \% \mathrm{FA}, 2 \% \mathrm{ACN} ; \mathrm{B}: \mathrm{ACN}+0.1 \% \mathrm{FA}$ & MS/MS & 2.71 & 2.46 \\
\hline PT9183 & alkaline & Waters, X-Bridge $\mathrm{C} 18,150 \times 3 \mathrm{~mm}$ & 150 & 17 & $\begin{array}{l}\text { A: } 6 \mathrm{mM} \text { Ammonium Hydroxide in } \mathrm{H}_{2} \mathrm{O} \text {; } \\
\text { B: } 6 \mathrm{mM} \text { Ammonium Hydroxide in } \mathrm{ACN}\end{array}$ & MS/MS & 6.34 & 4.98 \\
\hline PT9184 & acid & Waters Acquity UPLC BEH C18, $100 \times 2.1 \mathrm{~mm}, 1.7 \mu \mathrm{m}$ & 100 & 6.5 & A: $0.1 \%$ Formic Acid in UPW; B: $0.1 \%$ Formic Acid in ACN & MS/MS & 2.15 & 1.95 \\
\hline PT9185 & alkaline & Waters Acquity BEH C18, $100 \times 2.1 \mathrm{~mm}, 1.7 \mu \mathrm{m}$ & 100 & 6 & $\begin{array}{c}\mathrm{A}: \mathrm{H}_{2} \mathrm{O}+0.05 \% \text { ammonium hydroxide }(\mathrm{v} / \mathrm{v})+5 \mathrm{mmol} / \mathrm{L} \text { ammonium } \\
\text { acetate; } \mathrm{B}: \mathrm{MeOH}\end{array}$ & MS/MS & 3.48 & 3.23 \\
\hline PT9186 & acid & Phenomenex Kinetex PFP, $100 \AA, 75 \times 2.1 \mathrm{~mm}, 2.6 \mu \mathrm{m}$ & 75 & 16 & A: $0.1 \%$ Formic acid $\left(\mathrm{H}_{2} \mathrm{O}\right) ; \mathrm{B}: 0.1 \%$ Formic acid $(\mathrm{ACN})$ & MS/MS & 3.34 & 2.78 \\
\hline PT9187 & acid & Waters Acquity BEH-C18, $150 \times 2.1 \mathrm{~mm}, 1.7 \mu \mathrm{m}$ & 150 & 15 & $\mathrm{~A}: \mathrm{H}_{2} \mathrm{O}+0.1 \% \mathrm{FA} ; \mathrm{B}: \mathrm{ACN}+0.1 \% \mathrm{FA}$ & MS/MS & 10.6 & 6.4 \\
\hline PT9188 & acid & Waters Acquity BEH C18, $50 \times 2.1 \mathrm{~mm}, 1.7 \mu \mathrm{m}$ & 50 & 10 & A: $\mathrm{H}_{2} \mathrm{O}+$ formic acid $0.1 \% ; \mathrm{B}: \mathrm{ACN}+$ formic acid $0.1 \%$ & MS/MS & 2.5 & 2.8 \\
\hline
\end{tabular}

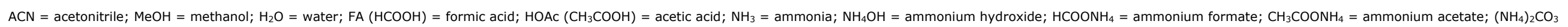

= ammonium carbonate; $\mathrm{NH}_{4} \mathrm{HCO}_{3}=$ ammoniumhydrogencarbonate; $\mathrm{NH}_{4} \mathrm{OH}=$ ammonium hydroxide. 


\begin{tabular}{|c|c|c|c|c|c|c|c|c|c|}
\hline $\begin{array}{l}\text { Lab } \\
\text { code }\end{array}$ & $\begin{array}{l}\text { Sample } \\
\text { weight } \\
\text { (g) }\end{array}$ & Extraction solvent & $\begin{array}{c}\text { Extraction } \\
\text { solvent } \\
\text { volume } \\
(\mathrm{ml})\end{array}$ & $\begin{array}{l}\text { Extraction } \\
\text { conditions }\end{array}$ & $\begin{array}{c}\text { Extraction } \\
\text { time } \\
\text { (min) }\end{array}$ & Sample clean-up & $\begin{array}{c}\text { SPE } \\
\text { cartridge }\end{array}$ & $\begin{array}{l}\text { Volume } \\
\text { extract } \\
\text { loaded on } \\
\text { SPE (ml) }\end{array}$ & $\begin{array}{c}\text { Matrix } \\
\text { equivalent } \\
\text { final extract } \\
(\mathrm{g} / \mathrm{ml})\end{array}$ \\
\hline PT9064 & 4 & $\mathrm{H}_{2} \mathrm{O}: \mathrm{ACN} 0.5 \% \mathrm{HCOOH}(50: 50, \mathrm{v} / \mathrm{v})$ & & mechanical shaking & 30 & other & & & 1 \\
\hline PT9152 & 2 & $\mathrm{ACN} / \mathrm{H}_{2} \mathrm{O} / \mathrm{FA} 50+50+1$ (vol.) & 20 & mechanical shaking & 30 & $\begin{array}{c}\text { other, shaking with } 4 \mathrm{~g} \\
\text { MgSO4 and } 1 \mathrm{~g} \mathrm{NaCl} \text {, } \\
\text { centrifugation, concentration } \\
2.5 \mathrm{ml} \text { (ACN layer) and } \\
\text { reconstitution in } 0,5 \mathrm{ml} \text { of } \\
\text { methanol/water/FA } 60+39+1 \\
\text { (vol.) }\end{array}$ & & & 0.5 \\
\hline PT9153 & 10 & $\mathrm{MeOH} / \mathrm{CH}_{2} \mathrm{Cl}_{2} / \mathrm{NH}_{3}$ & 100 & & 2 & $\mathrm{x}$ & & & $\begin{array}{c}10 \mathrm{~g} / 100 \mathrm{~mL}- \\
20 \mathrm{~mL} / 2 \mathrm{~mL}\end{array}$ \\
\hline PT9154 & 2 & $0.4 \%$ formic acid in $\mathrm{MeOH} / \mathrm{H}_{2} \mathrm{O}(60 / 40, \mathrm{v} / \mathrm{v})$ & 20 & & & filtration & & & \\
\hline PT9155 & 1 & $0.5 \%$ formic acid in $\mathrm{ACN} / \mathrm{H}_{2} \mathrm{O}(1: 1)$ & 4 & mechanical shaking & 30 & none & & & 0.25 \\
\hline PT9156 & 4 & $\mathrm{MeOH} / \mathrm{H}_{2} \mathrm{O} / \mathrm{FA}: 60: 40: 0.4$ & 40 & mechanical shaking & 30 & SPE & $\begin{array}{l}\text { SPE OASIS MCX } 150 \mathrm{mg}, 6 \\
\mathrm{ml}\end{array}$ & 10 & 2 \\
\hline PT9157 & & ACN/ ammoniumhydrogencarbonate & & & & SPE & Mycosep Romer Labs & & \\
\hline PT9158 & & $0.2 \%$ formic acid in $\mathrm{H}_{2} \mathrm{O}$ & & mechanical shaker & & SPE & & & \\
\hline PT9159 & 5 & ACN HPLC & 20 & mechanical shaking & 60 & none & & & 0.25 \\
\hline PT9160 & 2 & $\mathrm{MeOH} / \mathrm{H}_{2} \mathrm{O} /$ formic acid $(60 / 40 / 4)$ & 20 & mechanical shaking & 30 & dilution & & & 0.02 \\
\hline PT9161 & 1 & ACN, $0.05 \%$ formic acid in $\mathrm{H}_{2} \mathrm{O} 1: 1$ & 5 & $\begin{array}{c}\text { shaking } \\
\text { (hand/vortex) }\end{array}$ & 10 & other & & & 0,2 \\
\hline PT9162 & 2 & $\mathrm{ACN}+0.1 \% \mathrm{HCOOH}$ in $\mathrm{H}_{2} \mathrm{O}(1: 1)$ & 20 & mechanical shaking & 20 & dilution & & & 0.1 \\
\hline PT9163 & & Quechers extraction & $x$ & & & dSPE & & & \\
\hline PT9164 & 2.5 & $\mathrm{MeOH} / \mathrm{H}_{2} \mathrm{O} /$ formic acid 39/60/1 & 25 & mechanical shaking & 30 & none & & & \\
\hline \multicolumn{10}{|l|}{ PT9165 } \\
\hline PT9166 & 8 & $\mathrm{MeOH}$ (with $\mathrm{H}_{2} \mathrm{SO}_{4} 0.05 \mathrm{M}$ ) & 40 & ultrasonic & 15 & SPE & $\begin{array}{c}\text { HF Bond Elut LRC-SCX, } 500 \\
\text { mg Agilent }\end{array}$ & 10 & 2 \\
\hline PT9167 & 20 & $0.05 \mathrm{M}$ sulfuric acid in $\mathrm{MeOH}$ & 100 & ultrasonic & 15 & SPE & $\begin{array}{c}\text { Bond Elut Plexa PCX, } 500 \\
\text { mg } 6 \mathrm{ml} / \text { Agilent }\end{array}$ & $10 \mathrm{ml} / 1 \mathrm{ml}$ & 2 \\
\hline PT9168 & 1.5 & $\mathrm{MeOH} / \mathrm{H}_{2} \mathrm{O} /$ Formic acid $(60 / 40 / 0.4)$ & 25 & mechanical shaking & 30 & dilution & & & 0.012 \\
\hline PT9169 & 4 & $\mathrm{MeOH} / \mathrm{H}_{2} \mathrm{O} /$ formic acid solution $(75 / 25 / 0.4 \%)$ & 40 & mechanical shaking & 30 & SPE & $\begin{array}{c}\text { Strata-X-C } 200 \mathrm{mg} / 6 \mathrm{ml}, 33 \\
\mu \mathrm{m}\end{array}$ & 10 & 2 \\
\hline
\end{tabular}




\begin{tabular}{|c|c|c|c|c|c|c|c|c|c|}
\hline $\begin{array}{l}\text { Lab } \\
\text { code }\end{array}$ & $\begin{array}{l}\text { Sample } \\
\text { weight } \\
\text { (g) }\end{array}$ & Extraction solvent & $\begin{array}{l}\text { Extraction } \\
\text { solvent } \\
\text { volume } \\
\text { (ml) }\end{array}$ & $\begin{array}{l}\text { Extraction } \\
\text { conditions }\end{array}$ & $\begin{array}{l}\text { Extraction } \\
\text { time } \\
(\min )\end{array}$ & Sample clean-up & $\begin{array}{c}\text { SPE } \\
\text { cartridge }\end{array}$ & $\begin{array}{l}\text { Volume } \\
\text { extract } \\
\text { loaded on } \\
\text { SPE }(\mathrm{ml})\end{array}$ & $\begin{array}{c}\text { Matrix } \\
\text { equivalent } \\
\text { final extract } \\
(\mathrm{g} / \mathrm{ml})\end{array}$ \\
\hline РT9170 & 4 & $\mathrm{MeOH}$ (with $\mathrm{H}_{2} \mathrm{SO}_{4} 0.05 \mathrm{M}$ ) & 40 & mechanical shaking & 30 & none & & & \\
\hline PT9171 & 2 & $\mathrm{MeOH} / \mathrm{H}_{2} \mathrm{O} /$ Formic acid & 20 & ultrasonic & 30 & dilution & & & \\
\hline PT9172 & 2 & $\mathrm{MeOH}: \mathrm{H}_{2} \mathrm{O}:$ Formic acid $(39: 60: 1)$ & 20 & mechanical shaking & 60 & none & & & 0.1 \\
\hline PT9173 & 4 & $0.4 \%$ Formic acid in $\mathrm{MeOH}: \mathrm{H}_{2} \mathrm{O}(60: 40)$ & 40 & mechanical shaking & 60 & SPE & Oasis MCX & 6 & 0.3 \\
\hline PT9174 & 25 & ACN: $\mathrm{H}_{2} \mathrm{O}:$ Acetic acid $(79: 20: 1)$ & 100 & mechanical shaking & 30 & none & & & 0.25 \\
\hline PT9175 & 5 & $\mathrm{H}_{2} \mathrm{O}+\mathrm{ACN}(0.5 \%$ acetic acid $)$ & 20 & mechanical shaking & 30 & other & & & 1 \\
\hline PT9176 & 25 & ACN / Ammonium carbonate $0.2 \mathrm{~g} / \mathrm{l}(86 / 14)$ & 125 & mechanical shaking & 30 & SPE & $100 \mathrm{mg}$ dSPE Bondesil PSA & $2 \mathrm{ml} / 4 \mathrm{ml}$ & 0.1 \\
\hline PT9177 & $1-2$ & $\mathrm{MeOH} / \mathrm{H}_{2} \mathrm{O} 60: 40+4 \mathrm{ml} \mathrm{HCOOH} / \mathrm{l}$ & $20-50$ & mechanical shaking & 90 & none & " & & \\
\hline PT9178 & 4 & $0.4 \%$ formic acid in $\mathrm{MeOH} / \mathrm{H}_{2} \mathrm{O}(60 / 40, \mathrm{v} / \mathrm{v})$ & 40 & $\begin{array}{c}\text { shaking } \\
\text { (hand/vortex) }\end{array}$ & 30 & $\begin{array}{c}\text { Ultrafilter (Amicon Ultra-4 } \\
\text { Ultracel } 30 \mathrm{kD} \text { ) }\end{array}$ & & 2 & 0.1 \\
\hline PT9179 & & & & & $x$ & & & & \\
\hline PT9180 & 2 & $\mathrm{MeOH} / \mathrm{H}_{2} \mathrm{O} /$ formic acid $(60 / 40 / 0.4)$ & 8 & mechanical shaking & 15 & none & & & \\
\hline PT9181 & 10 & $0.05 \mathrm{M} \mathrm{H}_{2} \mathrm{SO}_{4}$ in $\mathrm{MeOH}$ & 100 & ultrasonic & 10 & SPE & $\begin{array}{l}\text { HF Bond Elute Plexa PCX; } \\
500 \mathrm{mg} / 6 \mathrm{ml}\end{array}$ & 10 & 1 \\
\hline PT9182 & 10 & $0.4 \%$ formic acid in $\mathrm{MeOH} / \mathrm{H}_{2} \mathrm{O}(60 / 40, \mathrm{v} / \mathrm{v})$ & 100 & mechanical shaking & 30 & $\begin{array}{l}\text { other, freeze out for at least } \\
2 \text { hours }\end{array}$ & & & 0,1 \\
\hline PT9183 & 4 & $0.4 \%$ formic acid in $\mathrm{MeOH}: \mathrm{H}_{2} \mathrm{O} 60: 40$ & 40 & mechanical shaking & 30 & other & N/A & N/A & 0.1 \\
\hline PT9184 & 2 & MeOH:UPW:Formic Acid (39:60:1) & 20 & $\begin{array}{c}\text { shaking } \\
\text { (hand/vortex) }\end{array}$ & 60 & $\begin{array}{l}\text { None, Sample was } \\
\text { centrifuged using a Costar } \\
\text { Spin X Tube and the } \\
\text { supernatant injected }\end{array}$ & & & 0.1 \\
\hline PT9185 & 4 & $\mathrm{MeOH} / \mathrm{H}_{2} \mathrm{O}(60: 40)+0.4 \%$ formic acid & 40 & mechanical shaking & 60 & none & N/A & N/A & 0.1 \\
\hline PT9186 & 2 & $\mathrm{MeOH} / \mathrm{H}_{2} \mathrm{O} /$ formic acid $(39: 60: 1)$ & 20 & mechanical shaking & 60 & none & & & 0.1 \\
\hline \multicolumn{10}{|l|}{ PT9187 } \\
\hline PT9188 & 1 & $\mathrm{H}_{2} \mathrm{O}+\mathrm{MeOH}$ & 10 & 30 & & filtration & & & \\
\hline
\end{tabular}

$\mathrm{ACN}=$ acetonitrile; $\mathrm{MeOH}=$ methanol; $\mathrm{H}_{2} \mathrm{O}=$ water; $\mathrm{CH}_{2} \mathrm{Cl}_{2}=$ dichloromethane; $\mathrm{H}_{2} \mathrm{SO}_{4}=$ sulfuric acid; $\mathrm{FA}(\mathrm{HCOOH})=$ formic acid; $\mathrm{HOAC}\left(\mathrm{CH}_{3} \mathrm{COOH}\right)=$ acetic acid; $\mathrm{NH}_{3}=$ ammonia; $\left(\mathrm{NH}_{4}\right)_{2} \mathrm{CO}_{3}=$ ammonium carbonate; $\mathrm{NH}_{4} \mathrm{HCO}_{3}=$ ammoniumhydrogencarbonate.

N/A: not applicable 


\section{Annex 9 Results: Material A (buckwheat flour)}

\begin{tabular}{|c|c|c|c|c|c|c|}
\hline \multicolumn{7}{|c|}{ Material A } \\
\hline & \multicolumn{2}{|c|}{ Atropine } & \multicolumn{2}{|c|}{ Scopolamine } & \multicolumn{2}{|c|}{ Sum } \\
\hline & \multicolumn{2}{|c|}{ A: $1.15 \mu \mathrm{g} / \mathrm{kg}$} & \multicolumn{2}{|c|}{ A: $1.16 \mu \mathrm{g} / \mathrm{kg}$} & \multicolumn{2}{|c|}{ A: $2.36 \mu \mathrm{g} / \mathrm{kg}$} \\
\hline & \multicolumn{2}{|c|}{ u: $0.049 \mu \mathrm{g} / \mathrm{kg}$} & \multicolumn{2}{|c|}{ u: $0.063 \mu \mathrm{g} / \mathrm{kg}$} & \multicolumn{2}{|c|}{ u: $0.099 \mu \mathrm{g} / \mathrm{kg}$} \\
\hline \multirow[b]{3}{*}{$\begin{array}{l}\text { Lab } \\
\text { code }\end{array}$} & \multicolumn{2}{|c|}{$\sigma_{p}: 0.287 \mu g / k g(25 \%)$} & \multicolumn{2}{|c|}{$\sigma_{p}: 0.290 \mu \mathrm{g} / \mathrm{kg}(25 \%)$} & \multicolumn{2}{|c|}{$\sigma_{p}: 0.591 \mu g / k g(25 \%)$} \\
\hline & \multicolumn{2}{|c|}{ robust $\sigma: 0.229 \mu \mathrm{g} / \mathrm{kg}(19.9 \%)$} & \multicolumn{2}{|c|}{ robust o: $0.297 \mu \mathrm{g} / \mathrm{kg}(25.6 \%)$} & \multicolumn{2}{|c|}{ robust $\sigma: 0.475 \mu \mathrm{g} / \mathrm{kg}(20.1 \%)$} \\
\hline & $\begin{array}{c}\text { Result } \\
(\mu \mathrm{g} / \mathrm{kg})\end{array}$ & z-score & $\begin{array}{c}\text { Result } \\
(\mu \mathrm{g} / \mathrm{kg})\end{array}$ & z-score & $\begin{array}{c}\text { Result } \\
(\mu \mathrm{g} / \mathrm{kg})\end{array}$ & z-score \\
\hline PT9064 & 0.9 & -0.87 & 0.4 & -2.62 & 1.3 & -1.80 \\
\hline PT9152 & 0.8 & -1.22 & 0.9 & -0.90 & 1.7 & -1.12 \\
\hline PT9153 & 1 & -0.52 & 0.88 & -0.97 & 1.9 & -0.79 \\
\hline PT9154 & 1.71 & 1.95 & 0.8 & -1.24 & 2.51 & 0.25 \\
\hline PT9155 & 1.4 & 0.87 & 1 & -0.55 & 2.4 & 0.06 \\
\hline PT9156 & 0.98 & -0.59 & 0.956 & -0.71 & 1.94 & -0.72 \\
\hline PT9157 & 1.029 & -0.42 & 1.347 & 0.64 & 2.376 & 0.02 \\
\hline РT9158 & 0.98 & -0.59 & 1.44 & 0.96 & 2.42 & 0.09 \\
\hline PT9159 & 0.99 & -0.56 & 1.18 & 0.07 & 2.17 & -0.33 \\
\hline PT9160 & $\mathrm{nd},<1$ & $(-0.52)$ & 1.87 & 2.45 & 1.87 & -0.84 \\
\hline РT9161 & 1.32 & 0.59 & 0.94 & -0.76 & 2.26 & -0.18 \\
\hline PT9162 & $<5$ & $(13.40)$ & $<5$ & (13.23) & $<5$ & $(4.46)$ \\
\hline PT9163 & 1.21 & 0.21 & 1.13 & -0.11 & 2.34 & -0.04 \\
\hline PT9164 & 0.93 & -0.76 & 1.16 & 0.00 & 2.09 & -0.46 \\
\hline PT9165 & $<5.0$ & $(13.40)$ & 2 & 2.89 & 7 & 7.84 \\
\hline PT9166 & 1.48 & 1.15 & 1.86 & 2.41 & 3.34 & 1.65 \\
\hline PT9167 & 1.12 & -0.10 & 1.14 & -0.07 & 2.26 & -0.18 \\
\hline PT9168 & 1.11 & -0.14 & 1.04 & -0.42 & 2.15 & -0.36 \\
\hline PT9169 & 0.99 & -0.56 & 0.99 & -0.59 & 1.98 & -0.65 \\
\hline PT9170 & 0.92 & -0.80 & 0.97 & -0.66 & 1.89 & -0.80 \\
\hline PT9171 & 1.14 & -0.03 & 0.963 & -0.68 & 2.1 & -0.45 \\
\hline PT9172 & 1.4 & 0.87 & 1.1 & -0.21 & 2.5 & 0.23 \\
\hline PT9173 & 0.97 & -0.62 & 1.04 & -0.42 & 2.01 & -0.60 \\
\hline PT9174 & 3.2 & 7.13 & $<2$ & (2.89) & 4.5 & 3.61 \\
\hline PT9175 & 12.8 & 40.54 & 0.31 & -2.93 & 13.1 & 18.16 \\
\hline PT9176 & 0.94 & -0.73 & 1.6 & 1.51 & 2.5 & 0.23 \\
\hline PT9177 & 1.07 & -0.28 & 1.01 & -0.52 & 2.08 & -0.48 \\
\hline PT9178 & 0.993 & -0.54 & 1.71 & 1.89 & 2.703 & 0.57 \\
\hline PT9179 & 1.3 & 0.52 & 1.3 & 0.48 & 2.6 & 0.40 \\
\hline PT9180 & 1.09 & -0.21 & 2.79 & 5.62 & 3.88 & 2.56 \\
\hline PT9181 & 1.4 & 0.87 & 1.5 & 1.17 & 2.9 & 0.91 \\
\hline PT9182 & 1.35 & 0.70 & 0.98 & -0.62 & 2.33 & -0.06 \\
\hline PT9183 & 0.96 & -0.66 & 0.98 & -0.62 & 1.94 & -0.72 \\
\hline PT9184 & 1.879 & 2.54 & 1.801 & 2.21 & 3.68 & 2.23 \\
\hline PT9185 & 1.04 & -0.38 & 1.01 & -0.52 & 2.05 & -0.53 \\
\hline PT9186 & 8.7 & 26.27 & 37.2 & 124 & 45.9 & 73.65 \\
\hline PT9187 & 1.17 & 0.07 & 1.29 & 0.45 & 2.46 & 0.16 \\
\hline PT9188 & $<5$ & $(13.40)$ & $<5$ & $(13.23)$ & & \\
\hline \multicolumn{7}{|c|}{$A=$ assigned value (robust mean) } \\
\hline \multicolumn{7}{|c|}{$\mathrm{u}=$ uncertainty of consensus value. } \\
\hline \multicolumn{7}{|c|}{$\sigma_{p}=$ target standard deviation for proficiency. } \\
\hline nd $=$ not $d$ & cta. & & & & & \\
\hline
\end{tabular}




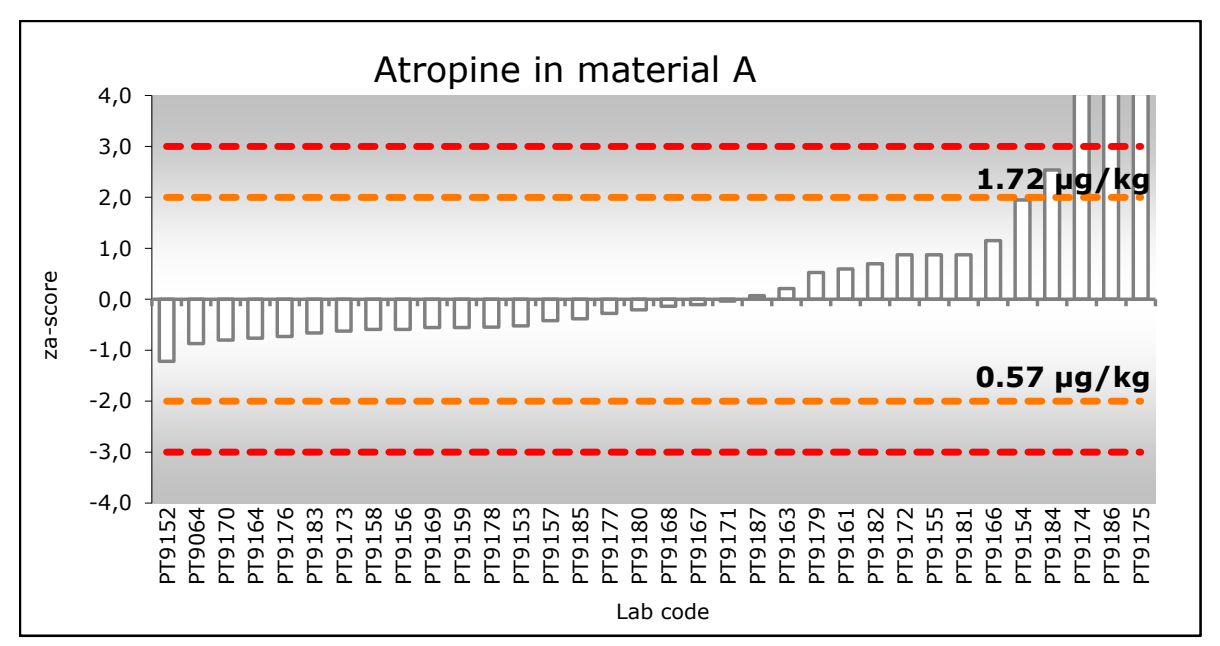

Figure 2 Graphical representation of the $z$-scores for atropine in the material A. Dotted lines show PT performance boundaries \pm 2 (also in $\mu \mathrm{g} / \mathrm{kg}$ ) and \pm 3 .

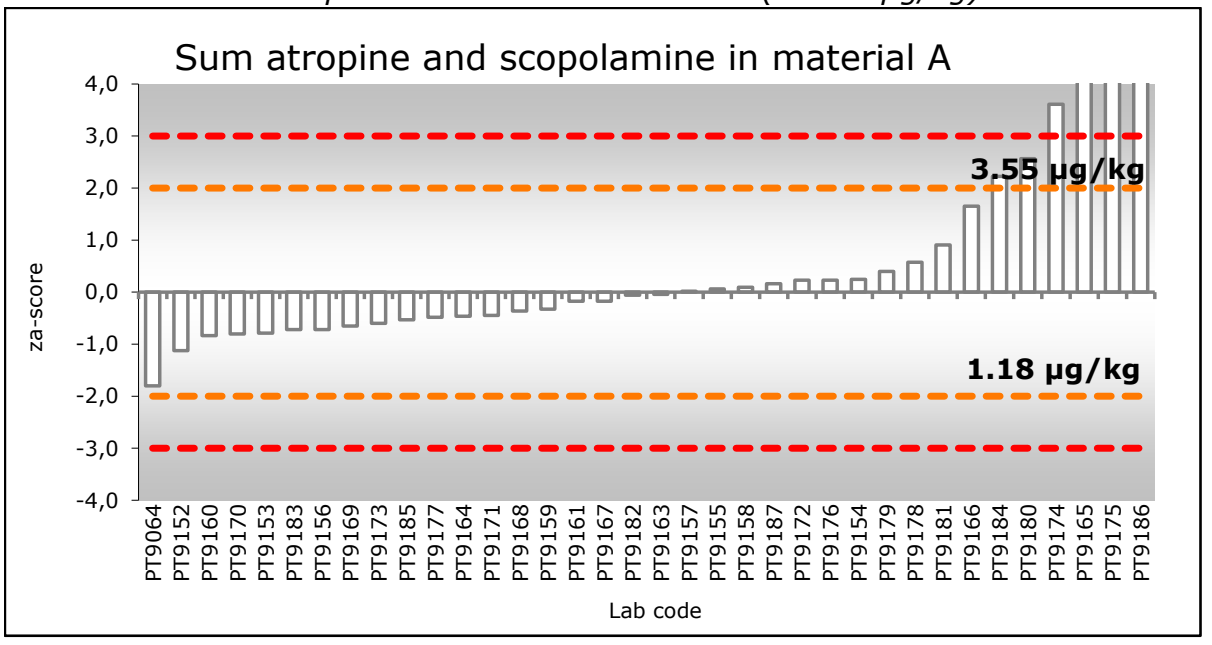

Figure 4 Graphical representation of the $z$-scores for the sum atropine and scopolamine in the material A. Dotted lines show PT performance boundaries \pm 2 (also in $\mu \mathrm{g} / \mathrm{kg}$ ) and \pm 3 .

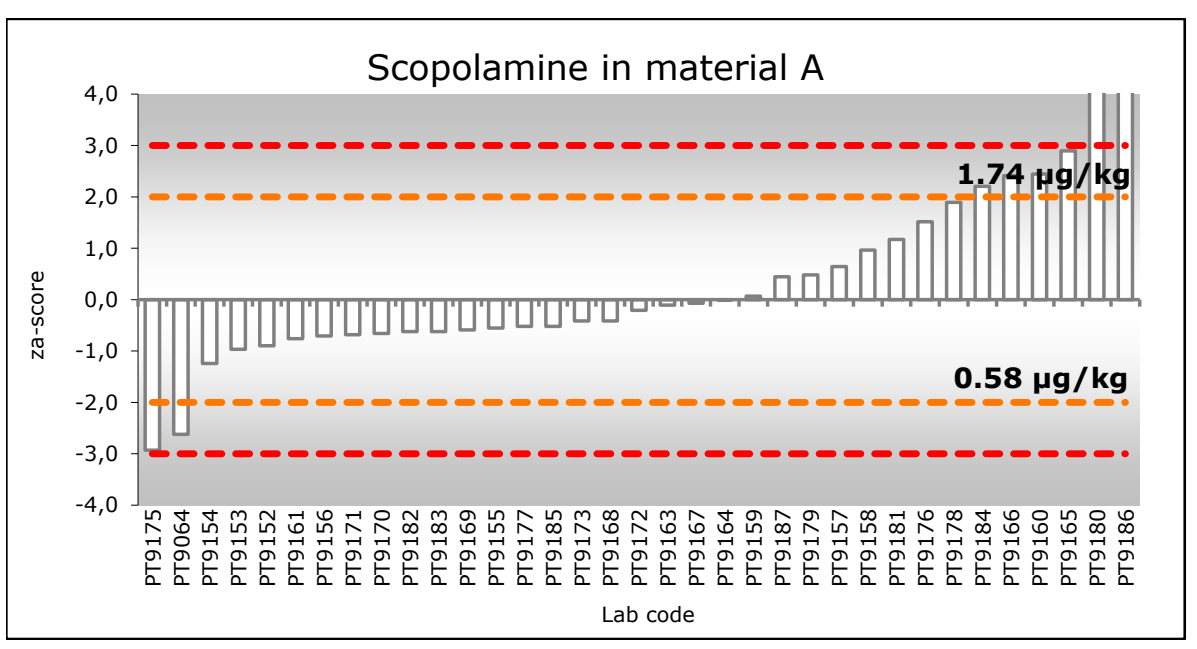

Figure 3 Graphical representation of the $z$-scores for scopolamine in the material A. Dotted lines show PT performance boundaries \pm 2 (also in $\mu \mathrm{g} / \mathrm{kg}$ ) and \pm 3 . 


\section{Annex 10 Results: Material B (maize flour)}

\begin{tabular}{|c|c|c|c|c|c|c|}
\hline \multicolumn{7}{|c|}{ Material B } \\
\hline & \multicolumn{2}{|c|}{ Atropine } & \multicolumn{2}{|c|}{ Scopolamine } & \multicolumn{2}{|c|}{ Sum } \\
\hline & \multicolumn{2}{|c|}{ A: $15.3 \mu \mathrm{g} / \mathrm{kg}$} & \multicolumn{2}{|c|}{ A: $52.7 \mu \mathrm{g} / \mathrm{kg}$} & \multicolumn{2}{|c|}{ A: $68.4 \mu \mathrm{g} / \mathrm{kg}$} \\
\hline & \multicolumn{2}{|c|}{ u: $0.439 \mu \mathrm{g} / \mathrm{kg}$} & \multicolumn{2}{|c|}{ u: $2.21 \mu \mathrm{g} / \mathrm{kg}$} & \multicolumn{2}{|c|}{ u: $2.35 \mu \mathrm{g} / \mathrm{kg}$} \\
\hline & \multicolumn{2}{|c|}{$\sigma_{p}: 3.81 \mu \mathrm{g} / \mathrm{kg}(25 \%)$} & & \multicolumn{2}{|c|}{$\sigma_{p}: 17.1 \mu \mathrm{g} / \mathrm{kg}(25 \%)$} \\
\hline \multirow[b]{2}{*}{$\begin{array}{l}\text { Lab } \\
\text { code }\end{array}$} & \multicolumn{2}{|c|}{ robust o: $2.11 \mu \mathrm{g} / \mathrm{kg}(13.8 \%)$} & \multicolumn{2}{|c|}{ robust o: $10.6 \mu g / \mathrm{kg}(20.1 \%)$} & \multicolumn{2}{|c|}{ robust o: $11.4 \mu \mathrm{g} / \mathrm{kg}(16.7 \%)$} \\
\hline & $\begin{array}{c}\text { Result } \\
(\mu \mathrm{g} / \mathrm{kg})\end{array}$ & z-score & $\begin{array}{c}\text { Result } \\
\text { ( } \mu \mathrm{g} / \mathrm{kg})\end{array}$ & z-score & $\begin{array}{c}\text { Result } \\
\text { ( } \mu \mathrm{g} / \mathrm{kg})\end{array}$ & z-score \\
\hline PT9064 & 2.8 & -3.27 & 32.7 & -1.52 & 35.5 & -1.92 \\
\hline PT9152 & 15.3 & 0.01 & 61.3 & 0.65 & 76.6 & 0.48 \\
\hline PT9153 & 16 & 0.20 & 52 & -0.05 & 68 & -0.02 \\
\hline PT9154 & 14.8 & -0.12 & 45.1 & -0.58 & 59.9 & -0.50 \\
\hline PT9155 & 16.3 & 0.28 & 37.4 & -1.16 & 53.7 & -0.86 \\
\hline PT9156 & 13.8 & -0.38 & 47.7 & -0.38 & 61.5 & -0.40 \\
\hline PT9157 & 10.587 & -1.22 & 62.375 & 0.74 & 72.962 & 0.27 \\
\hline PT9158 & 13.7 & -0.41 & 58.3 & 0.43 & 72 & 0.21 \\
\hline PT9159 & 14.74 & -0.13 & 45.85 & -0.52 & 60.59 & -0.46 \\
\hline PT9160 & 15 & -0.07 & 48.3 & -0.33 & 63.3 & -0.30 \\
\hline PT9161 & 17.4 & 0.56 & 43.29 & -0.71 & 60.69 & -0.45 \\
\hline PT9162 & 18.08 & 0.74 & 56.71 & 0.31 & 74.79 & 0.37 \\
\hline PT9163 & $\mathrm{nt}$ & & $\mathrm{nt}$ & & nt & \\
\hline PT9164 & 13.63 & -0.43 & 60.52 & 0.59 & 74.15 & 0.34 \\
\hline PT9165 & 15 & -0.07 & 45 & -0.58 & 60 & -0.49 \\
\hline PT9166 & 13.87 & -0.36 & 48.13 & -0.35 & 62 & -0.38 \\
\hline PT9167 & 16.3 & 0.28 & 50.2 & -0.19 & 66.5 & -0.11 \\
\hline PT9168 & 16.1 & 0.22 & 48.1 & -0.35 & 64.2 & -0.25 \\
\hline PT9169 & 13.6 & -0.43 & 43.2 & -0.72 & 56.8 & -0.68 \\
\hline PT9170 & 16.4 & 0.30 & 52.5 & -0.01 & 68.9 & 0.03 \\
\hline PT9171 & 16.95 & 0.45 & 65.45 & 0.97 & 82.4 & 0.82 \\
\hline PT9172 & 18.6 & 0.88 & 70.4 & 1.34 & 89 & 1.20 \\
\hline PT9173 & 11.32 & -1.03 & 49.41 & -0.25 & 60.73 & -0.45 \\
\hline PT9174 & 17.4 & 0.56 & 53 & 0.02 & 70.4 & 0.12 \\
\hline PT9175 & 233 & 57.11 & 32.7 & -1.52 & 266 & 11.55 \\
\hline PT9176 & 13 & -0.59 & 66 & 1.01 & 79 & 0.62 \\
\hline PT9177 & 14.9 & -0.09 & 50.8 & -0.14 & 65.7 & -0.16 \\
\hline PT9178 & 13.48 & -0.46 & 73.1 & 1.55 & 86.58 & 1.06 \\
\hline PT9179 & 8.5 & -1.77 & 38.7 & -1.06 & 47.2 & -1.24 \\
\hline PT9180 & 18.05 & 0.73 & 98.56 & 3.48 & 116.61 & 2.82 \\
\hline PT9181 & 18.5 & 0.85 & 62.1 & 0.71 & 80.6 & 0.71 \\
\hline PT9182 & 15.65 & 0.10 & 52.16 & -0.04 & 67.81 & -0.04 \\
\hline PT9183 & 15.6 & 0.09 & 51.2 & -0.11 & 66.8 & -0.09 \\
\hline PT9184 & 17.212 & 0.51 & 61.501 & 0.67 & 78.713 & 0.60 \\
\hline PT9185 & 14.33 & -0.24 & 44.4 & -0.63 & 58.73 & -0.57 \\
\hline PT9186 & $<0.5$ & $(-3.87) \mathrm{FN}$ & $<0.5$ & $(-3.96) \mathrm{FN}$ & 0.62 & -3.96 \\
\hline PT9187 & 14.9 & -0.09 & 54.8 & 0.16 & 69.8 & 0.08 \\
\hline PT9188 & 15.1 & -0.04 & 83.4 & 2.33 & 98.5 & 1.76 \\
\hline$A=$ assigr & value (robust & & & & & \\
\hline $\mathrm{u}=$ uncer & inty of consensu & & & & & \\
\hline$\sigma_{p}=$ target & tandard deviatio & ficiency. & & & & \\
\hline nt $=$ not te & & & & & & \\
\hline
\end{tabular}




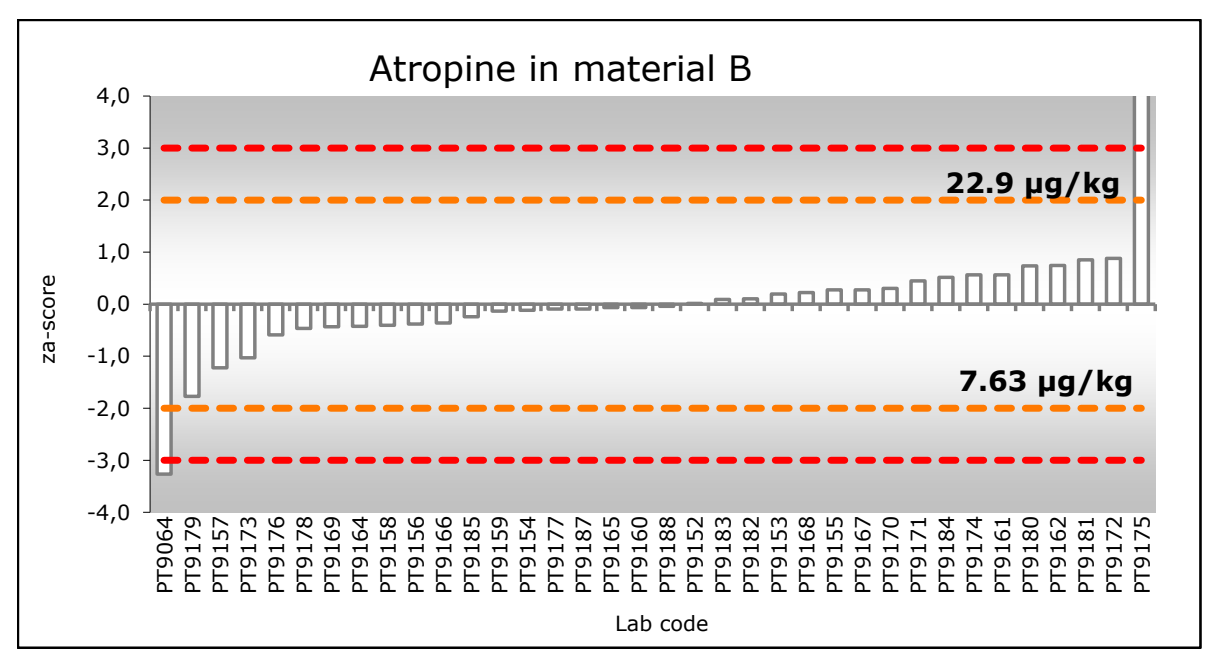

Figure 5 Graphical representation of the $z$-scores for atropine in the material $B$. Dotted lines show PT performance boundaries \pm 2 (also in $\mu \mathrm{g} / \mathrm{kg}$ ) and \pm 3 .

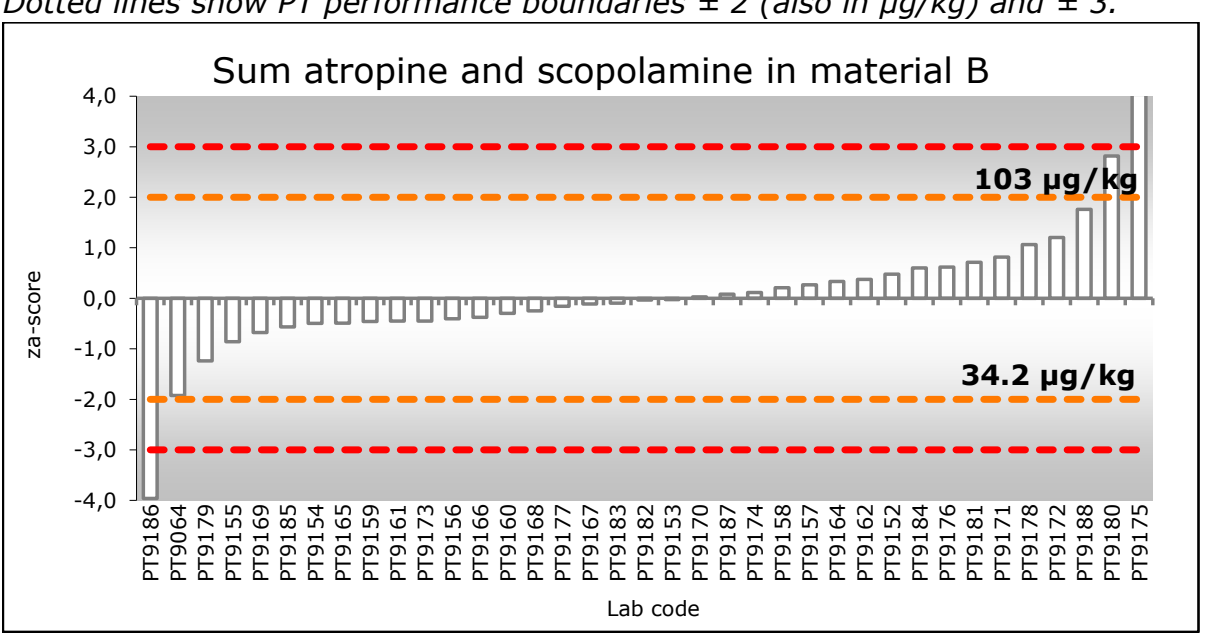

Figure 7 Graphical representation of the $z$-scores for the sum of atropine and scopolamine in the material B. Dotted lines show PT performance boundaries \pm 2 (also in $\mu \mathrm{g} / \mathrm{kg}$ ) and \pm 3 .

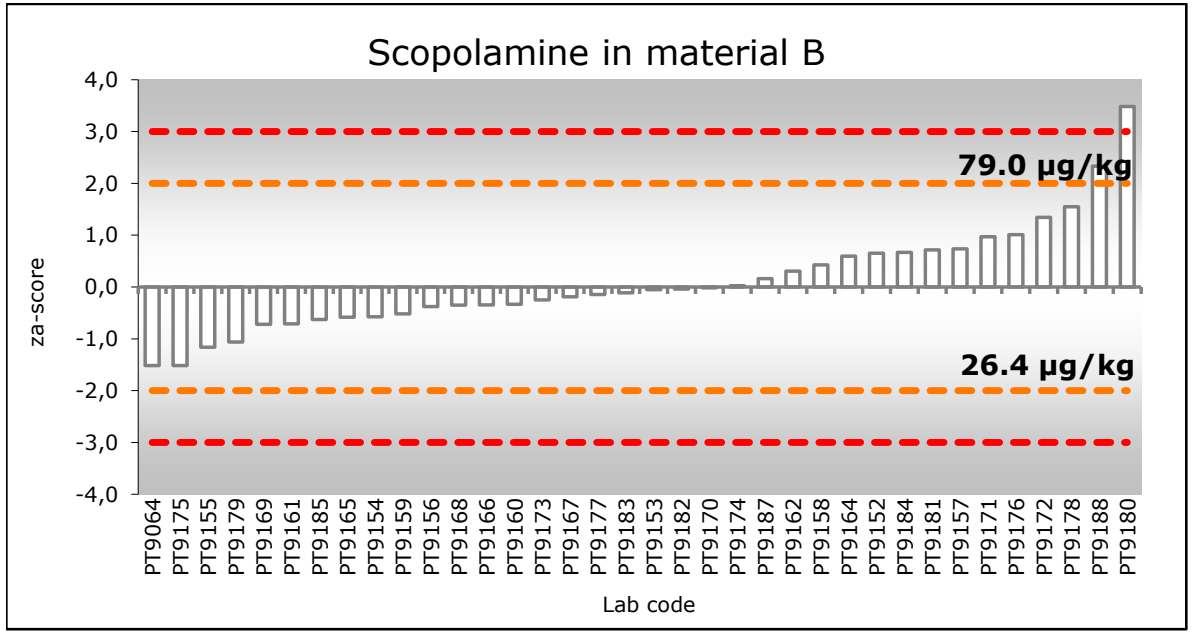

Figure 6 Graphical representation of the $z$-scores for scopolamine in the material B. Dotted lines show PT performance boundaries \pm 2 (also in $\mu \mathrm{g} / \mathrm{kg}$ ) and \pm 3 . 


\section{Annex 11 Overview performance per participant}

\begin{tabular}{|c|c|c|}
\hline Participant code & $\begin{array}{l}\text { Individual tropane alkaloids } \\
\text { Satisfactory performance * }\end{array}$ & $\begin{array}{c}\text { Sum } \\
\text { Satisfactory performance * }\end{array}$ \\
\hline PT9064 & 2 out of 4 & 2 out of 2 \\
\hline PT9152 & 4 out of 4 & 2 out of 2 \\
\hline PT9153 & 4 out of 4 & 2 out of 2 \\
\hline PT9154 & 4 out of 4 & 2 out of 2 \\
\hline PT9155 & 4 out of 4 & 2 out of 2 \\
\hline PT9156 & 4 out of 4 & 2 out of 2 \\
\hline PT9157 & 4 out of 4 & 2 out of 2 \\
\hline PT9158 & 4 out of 4 & 2 out of 2 \\
\hline PT9159 & 4 out of 4 & 2 out of 2 \\
\hline PT9160 & 2 out of 4 & 2 out of 2 \\
\hline PT9161 & 4 out of 4 & 2 out of 2 \\
\hline PT9162 & 2 out of 4 & 1 out of 2 \\
\hline PT9163** & 2 out of $2 * *$ & 1 out of $1 * *$ \\
\hline PT9164 & 4 out of 4 & 2 out of 2 \\
\hline PT9165 & 2 out of 4 & 1 out of 2 \\
\hline PT9166 & 3 out of 4 & 2 out of 2 \\
\hline PT9167 & 4 out of 4 & 2 out of 2 \\
\hline PT9168 & 4 out of 4 & 2 out of 2 \\
\hline PT9169 & 4 out of 4 & 2 out of 2 \\
\hline PT9170 & 4 out of 4 & 2 out of 2 \\
\hline PT9171 & 4 out of 4 & 2 out of 2 \\
\hline PT9172 & 4 out of 4 & 2 out of 2 \\
\hline PT9173 & 4 out of 4 & 2 out of 2 \\
\hline PT9174 & 2 out of 4 & 1 out of 2 \\
\hline PT9175 & 1 out of 4 & 0 out of 2 \\
\hline PT9176 & 4 out of 4 & 2 out of 2 \\
\hline PT9177 & 4 out of 4 & 2 out of 2 \\
\hline PT9178 & 4 out of 4 & 2 out of 2 \\
\hline PT9179 & 4 out of 4 & 2 out of 2 \\
\hline PT9180 & 2 out of 4 & 0 out of 2 \\
\hline PT9181 & 4 out of 4 & 2 out of 2 \\
\hline PT9182 & 4 out of 4 & 2 out of 2 \\
\hline PT9183 & 4 out of 4 & 2 out of 2 \\
\hline PT9184 & 2 out of 4 & 1 out of 2 \\
\hline PT9185 & 4 out of 4 & 2 out of 2 \\
\hline PT9186 & 0 out of 4 & 0 out of 2 \\
\hline PT9187 & 4 out of 4 & 2 out of 2 \\
\hline PT9188 & 1 out of 4 & 1 out of 2 \\
\hline
\end{tabular}


Wageningen Food Safety Research

P.O. Box 230

6700 AE Wageningen

The Netherlands

T +31 (0)317480256

www.wur.eu/food-safety-research

WFSR report 2021.005
The mission of Wageningen University \& Research is "To explore the potential of nature to improve the quality of life". Under the banner Wageningen University \& Research, Wageningen University and the specialised research institutes of the Wageningen Research Foundation have joined forces in contributing to finding solutions to important questions in the domain of healthy food and living environment. With its roughly 30 branches, 6,500 employees (5,500 fte) and 12,500 students, Wageningen University \& Research is one of the leading organisations in its domain. The unique Wageningen approach lies in its integrated approach to issues and the collaboration between different disciplines. 



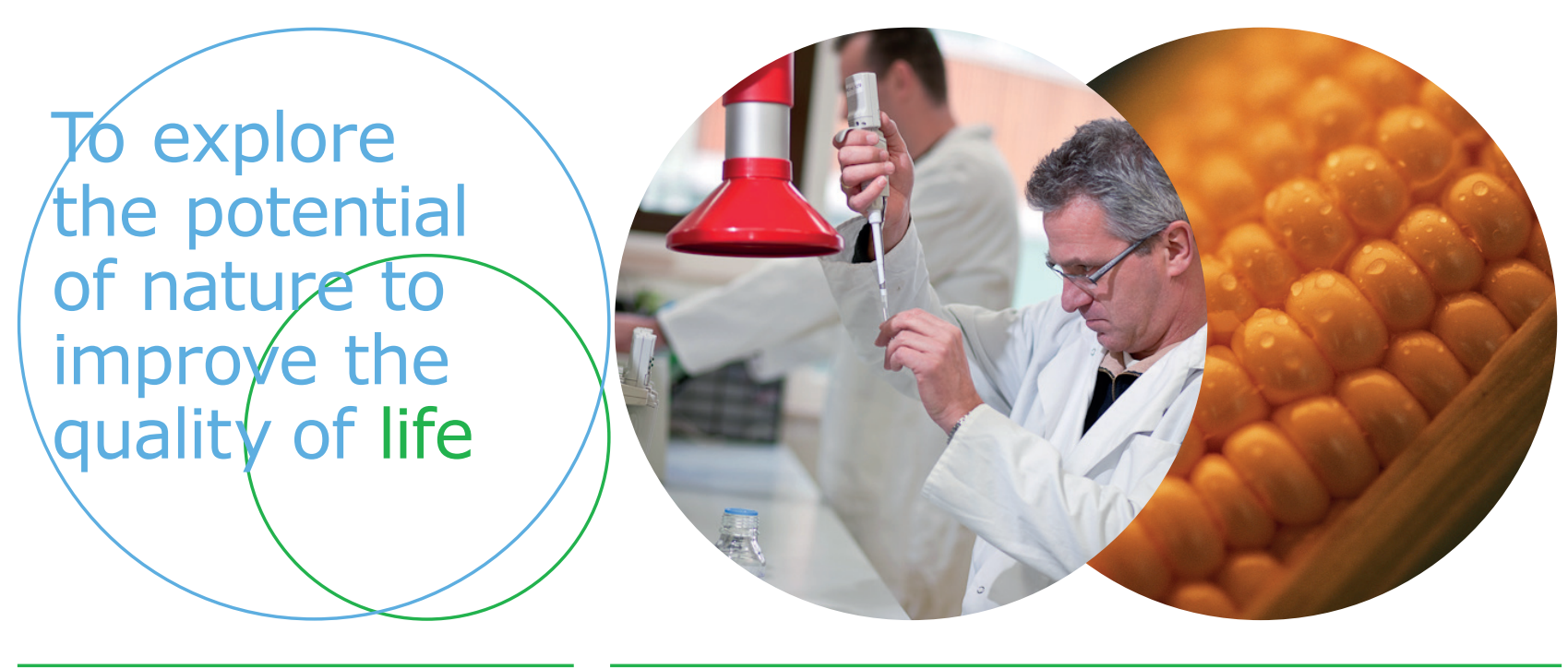

Wageningen Food Safety Research P.O. Box 230

6700 AE Wageningen

The Netherlands

T +31 (0)317480256

www.wur.eu/food-safety-research

WFSR report 2021.005
The mission of Wageningen University \& Research is "To explore the potential of nature to improve the quality of life". Under the banner Wageningen University $\&$ Research, Wageningen University and the specialised research institutes of the Wageningen Research Foundation have joined forces in contributing to inding solutions to important questions in the domain of healthy food and living environment. With its roughly 30 branches, 6,500 employees (5,500 fte) and 12,500 students, Wageningen University \& Research is one of the leading organisations in its domain. The unique Wageningen approach lies in its integrated approach to issues and the collaboration between different disciplines. 